Article

\title{
Resilience and Creativity in Teenagers with High Intellectual Abilities. A Middle School Enrichment Experience in Vulnerable Contexts
}

\author{
Gabriela López-Aymes ${ }^{1, * \mathbb{C}}$, Santiago Roger Acuña ${ }^{2}$ and Gabriela Ordaz Villegas ${ }^{3}$ \\ 1 Centre for Transdisciplinary Research in Psychology, Autonomous University of the State of Morelos, \\ Cuernavaca, Morelos 62350, Mexico \\ 2 Faculty of Communication Sciences, Autonomous University of San Luis Potosí, San Luis Potosí 78216, Mexico; \\ santiagoacu1@gmail.com \\ 3 Faculty of Higher Studies Zaragoza, National Autonomous University of Mexico, Mexico City 09230, Mexico; \\ gabriela.ordaz@zaragoza.unam.mx \\ * Correspondence: gabriela.lopez@uaem.mx; Tel.: +52-777-329-7970
}

Received: 30 June 2020; Accepted: 19 August 2020; Published: 17 September 2020

\begin{abstract}
This article presents and describes an extracurricular enrichment intervention program to promote the development of resilience factors, aimed at teenagers with high abilities from vulnerable social contexts. In addition, its effects on aspects related to creativity and resilience are explored. This program proposes a series of creative and meaningful activities so that students can explore, experiment, express their emotions and analytically contrast their own identity characteristics with their surrounding reality. A comparative case study was carried out with a mixed methodological approach. Three students (two male and one female) of 13 and 14 years of age and with high abilities, who attended a public middle school located in a disadvantaged sector of the Mexican capital, participated. The program was developed over nine sessions (90 min each), over two months. The quantitative analysis did not show significant differences in the creativity and resilience factors. However, the qualitative analysis of the tasks and products created by the participants has provided positive evidence about the program's contribution to enhancing their self-knowledge and coping skills, considering the adversities of their family, school and social contexts.
\end{abstract}

Keywords: resilience; creativity; high intellectual ability; adolescence; vulnerable context

\section{Introduction}

Resilience can be understood, from an ecosystem point of view of human development, as a dynamic and multidimensional process that people unfold in their quest to reach a positive adjustment to immediate adversity [1,2]. This concept is a paradigm shift in the comprehension of the human being, because it emphasizes potential in the range of resources and the relations of people with their contextual environment. Resilience is a complex and interactive phenomenon that cannot be explained only as a fixed personal characteristic, or as depending on a certain variable, but is the result of the whole frame of dynamic transactions between multiple factors that correspond to individual and contextual dimensions, whether personal, family, socio-community, or cultural characteristics [3].

In each one of these dimensions, there are protective and risk factors. Risk factors are those conditions biological, psychological, cognitive or environmental conditions that hinder integral development and make people more vulnerable to certain situations in their lives [4,5]. For example, a low level of intelligence (personal), any family dysfunction (family), a social context of poverty (social), or a racist society (cultural) can represent risk factors. Protective factors have to do with the characteristics, resources and support that help buffer the response of people to the same events in life. 
A positive self-esteem and self-efficacy, family cohesion, systemic community support and tolerant culture are examples of protective factors: personal, familial, social, and cultural, respectively.

The research about resilience tried to identify the presence of both factors of these dimensions through the study of people that belong to vulnerable groups, that have unfavorable situations (refugees), or that have experienced traumatic and critical situations (abuse, neglect) [1,2,6,7].

In recent decades, an ecological system approach has been taken [8] which is more focused on the transactional processes of resilience that are established between the different risk and protective factors of these dimensions [3,6,9]. Resilience can be better understood if it's examined as the result of these transactions "within" and "between" the multiple system levels over the years $[2,3,10]$. Therefore, it is a dynamic process rather than a linear one, which can shift constantly as people and their contexts' subsystems are transformed. For example, the theoretical Relational-Cultural (ECA) perspective about resilience $[3,10]$ is used to understand the complex interpersonal and cultural dynamics with many dimensions that affect people's ability to be resilient, and allows us to go deeper, not only into the dynamic and nonlinear qualities of resilience, but also into its idiosyncratic, universal, modulated, and modifiable character through a mediational intervention.

Specifically, about the relative and idiosyncratic character of resilience, Rutter [11] has pointed out that in a determined situation, a risk factor may cease and become a protective factor depending on the interpretation of a situation in a given cultural context. Therefore, the vulnerable areas of a person or social group are idiosyncratic expressions of "risk", which may be mitigated by compensatory strategies that support links with other significant people [12].

Likewise, resilience is not a process that is only activated in the face of extraordinarily adverse situations, nor is it a characteristic of certain individuals or specific groups. However, throughout their life, any person can find themselves in adverse situations and activate resilience responses successfully. However, the same person may respond differently to the same adversities at another time in their life, or to a different stressful or adverse situation [13]. In addition, what can be considered risk and/or protective factors for one individual may not be so for another with a different predisposition, in terms of characteristics and environment [7,14].

Regarding the predisposition to resilience, a key factor is the coping mechanism. For Manciaux [15], resilience consists of a stable and structured practice of coping answers, which is to say, it consists of many successive strategies in different behavior domains that altogether constitute a state, both for resistance to events and for the building and development of a life project. So, coping would be the first step of resilience and the set of coping strategies is what allows one to keep building a more durable state with higher levels of systematization and structuring [15].

Current theoretical approaches about resilience have highlighted that it can be modulated through the promotion of resilience factors [10]. Therefore, it becomes more relevant not only to identify the interplay between risk and protective factors, but especially to implement support and compensatory strategies [16] that fundamentally allow the strengthening of the protective factors as much as the promotion of resilience factors $[3,10,17]$. These factors, unlike the first ones, do not protect one from risk, but are the ones that allow one to confront it-for example, by having a significant other that gives unconditional affective support [18]. This support would be understood more as a resilience factor and not as a protective factor because it does not act directly against the risk [17]. In this regard, the implementation of strategies of intervention in schools to promote resilience plays an important role because it is possible to promote coping strategies within the students that enable them to be resilient and to favor the development of social, academic and personal abilities that help the students to overcome such situations and succeed in life by exploiting their potential $[19,20]$. For example, Cyrulnik [21] has highlighted the importance of "resilience tutors", which include anything (a person, a place, an event, a work of art) that can strengthen a person's psychological development and contribute to overcoming the unfavorable circumstances they may encounter in the future.

On the other hand, in Grotberg's interactive model [22] resilience has been analyzed through the development of personal competences, which are manifested in the relationship that can be established 
with others, considering three fundamental categories: (a) the support that the person believes he can receive (I have); (b) the intra-psychic strengths and the internal conditions which he defines himself (I am); and (c) the skills to interact and problem solving (I can). In turn, Saavedra [23,24], in his emergent model of resilience, has identified a number of specific factors for each of these three major dimensions. For example, some factors that fall within Grotberg's "I am" dimension [22], Saavedra points to the identity (referring to what and how a person stably defines himself or herself by the facts and actions that he or she displays throughout his or her life in accordance with the values of his or her culture); autonomy (i.e., independence of action; such as satisfaction); self-esteem and feeling of achievement that a person has when trying to respond to a critical situation, and coping (positive orientation towards action). Likewise, the "I have" dimension includes factors such as: goals (the meaning of an action) bonds and networks (the types of interpersonal, family, social support and the accompanying affective and value judgments, among others). Additionally, for the third dimension "I can" factors such as: self-efficacy (the self-perception of one's own capacity); learning (both an understanding of the problematic situation and an opportunity to learn); and, generativity (the ability to ask for support from others) are considered.

In this emerging model of Saavedra $[23,24]$ the factors also refer in a focused way of this areas of depth, namely: (a) basic conditions, which refer to the system of beliefs and links already consolidated at a certain point, which are the basis that supports the other areas, such as the identity factor; (b) visions of oneself and of the problem, which allude to the positive affective and cognitive elements for interpreting the person and the problem situation, corresponding to these types of factors, autonomy and satisfaction, respectively; and, (c) the resilient response, relating to the way of acting and facing up to adverse situations, in which case, the action goals allude to this area. In this Respect, involvement in creative activities or the development of people's creative potential can be a very appropriate way of promoting resilience factors [25-27]. For example, Metzl and Morrell [25] have highlighted the role of personal creativity in resilience processes. Similarly, Thomson [28] has highlighted a very strong relationship between resilience and creativity. Firstly, both concepts involve personal and cultural components. On the one hand, it has been proven that resilient people and creative people share personal characteristics, such as flexibility, initiative, resourcefulness, adaptability, spontaneity and originality, for example $[25,29]$. However, also, both concepts imply a range of contextual factors, from the establishment of active links with other significant ones to the existence of familiar and contextual supports that allow them the freedom to undertake something new [25,30,31].

The similarities in some personal characteristics and profiles of creative and resilient people imply frequent activation of similar mental processes, such as adaptive cognition [25,28,32]. Adaptive cognition refers to ways and tactics of thinking and acting which are conducive to the well-being of oneself and others, and it involves a high degree of metacognitive component, since it involves the use of thinking strategies that lead to the achievement of fulfilling full and useful life [32]. Another shared process common to both concepts is emotional flexibility [33,34]. Thus, it has been pointed out that resilient people can cope with critical situations, using humor, creative exploration and optimistic thinking [34]. In other words, they activate a series of positive emotions and are able to focus on them and associate them productively with their personal characteristics and the circumstances they are going through. This allows them to consider the problem from a constructive approach and face adversities in a more optimistic and enthusiastic way [34].

It has also been found that divergent thinking, one of the central processes of creativity, is another process that is activated in both resilience and creativity. This process refers to an aspect of psychological flexibility that makes it possible to understand problems from various points of view to activate various explanations and find possible solutions to them [35,36]. In this regards, divergent thinking [37] has also been associated with mental mechanisms that resilient people use to overcome critical situations, as well as self-awareness and emotional expressiveness [26]. In addition, both creative and resilient people are able to distance themselves from stressful stimuli when they are in the flow experience and find pleasure in being engaged in an activity that interests them, without expecting external rewards 
for it. Consequently, in this autotelic experience, positive emotions are activated, personal skills are put into action, and self-confidence is increased [38].

The importance of contextual aspects, as in the case of resilience, has been constantly highlighted by research on creativity. Different theoretical models on creativity have highlighted its multidimensional character $[30,39]$. Not only when defining creativity as a characteristic of the creative product, as in the case of Plucker, Beghetto and Dow [40], who point out that a result is creative when it meets the criteria of originality and appropriateness, provided that these features are determined by a specific socio-cultural and historical context. This multidimensional characteristic also becomes present when creativity are examined and particularized with a systemic view. They also examine and particularize their different dimensions with a systemic view, in the same way as Sternberg and Lubart [30] which gives a relevant weight to the environment, in addition to personal characteristics and features, processes and the product. The existence of an immediate context that provides support and containment is also key to realizing people's creative potential; in other words, an environment that encourages and supports a person's involvement in activities geared towards the new [40].

This is why there is a close association between creativity and resilience; early studies on resilience have considered creativity as a type or a factor of resilience [41]. Wolin and Wolin [41] consider humor and creativity as key capacities that allow positive, fun and even beautiful aspects to be found in the midst of adversity and chaos, and which become evident especially once adversity has been overcome. Moreover, for Metzl and Morrel [25], creativity can be seen as a personality trait of resilient people, and therefore plays a fundamental role in the conceptualization of resilience as a multifactorial process. For example, intellectual curiosity, high levels of commitment, self-confidence and emotional involvement, attraction to complexity and difference are some of the main personality traits that resilient and creative people may share $[25,26,29]$.

Scientific research has found significant correlations and associations between different specific aspects of creativity and resilience. De Caroli and Sagone [42] found significant relationships between creative personality traits and commitment, competence and adaptability in Italian adolescents; the more they perceived themselves as creative, the more they tended to be committed and competent in finding new solutions to problems in a resilient way. Hence, they postulate a "creative resilience", which according to their levels can positively or negatively influence the outcomes of people's development and growth, in different domains of everyday life, such as academic performance, career choice and job satisfaction, close relationships.

Creativity has also been considered a predictor and as a factor that modulates between emotional and identity aspects and resilience [25,43]. In this sense, a recent study [43] of secondary school students in China showed not only the existence of positive, moderately significant correlation between positive emotions, creativity and resilience, but also that creativity acts as a mediating variable between these positive emotions and the capacity of students to be resilient when learning a third language; that is, when students experience emotions, for example those linked to feeling good and happy, they perceive and face learning contexts with a creative and flexible perspective.

On the other hand, it is important to note that the stress and difficulties adolescents go through can affect their creativity and resilience, but also, situational threat can have positive components. Several studies [44,45] argue that situational stress decreases divergent thinking, because stress induces a tendency to rely on established responses and routines, or because it induces cognitive rigidity [46]. Kruglanski and colleagues found that stress often induces a need for closure that inhibits the flow of ideas, a critical component of creative thinking [47].

Situational threat, on the other hand, can motivate creative behavior. Anecdotal evidence shows that many inventions occurred during times of war or urgent need [48,49]. Experimental research [50] is consistent with the idea that conflict enhances creativity in matters that are relevant to conflict. Other researchers also found that stress is a facilitator of the creative process [51], particularly when the level of stress is modest, and the situation is controllable [52]. Stress can improve sensitivity to the nature of the creative problem [53]. 
Walton and Kemmelmeier [54] explain that the threat mobilization hypothesis argues that it is precisely under conditions of urgency and threat that individuals are motivated to explore new solutions to solve pressing problems. For example, in times of war or impending disaster, and with access to limited resources, people have often generated technologies and ad hoc solutions that have proven to be highly successful.

Runco [53] found out that the threat can increase the sensitivity or prominence of a problem and provide the motivation to seek an innovative solution. This approach can result in improved creative performance. In addition, in other studies [51], stress is considered beneficial for the creative process, and its own resilience.

In addition, a synergistic link between the two concepts could be considered, which enhance each other. In other words, providing tools for people to be more creative can strengthen their capacity for resilience and, in addition, by achieving a higher degree of resilience, people can use and benefit from their creative potential.

It is not surprising that providing support in schools to enhance students' resilient capacities is an appropriate intervention strategy to advance the educational and social inclusion of all students $[12,19,33]$. In this regard, it can be very appropriate for the comprehensive development of students with different abilities, such as high ability students.

Indeed, same as anyone else, people with high intellectual abilities can show and benefit from resilience in their lives, and they are likely to deal with adverse situations as well. Not only in their family and community contexts may there be situations of risk, family violence or schools with low educational quality [55] or be part of vulnerable social groups or marginalized communities [56], but they may also present a double exception, a combination of high intellectual abilities with specific difficulties in another area of their development [57]. In this regard, some research has addressed the issue of high abilities by relating them to protective and risk factors associated with resilience $[58,59]$.

From a resilient approach, according to Neihart [58], high abilities are a protective factor, because they involve a series of internal resources that make people with these characteristics more resilient, and allow them to overcome adverse and stressful events that may occur in their lives. But at the same time, from a risk approach, some of the internal distinctive notes such as asynchronous development, emotional intensity, and especially the interpretations and responses provided in the immediate contexts of these people, can place them in a situation of vulnerability and hinder the development of their potentialities [58]. In this regard, several studies [58-60], identified the obstacles experienced by young people with high by taking into account perceptions of achievement and cultural conflict in their immediate contexts, but also attempted to identify the common characteristics that children with high abilities share with resilient children.

Neihart [61] pointed out that some of these personal characteristics are curiosity, self-efficacy, sense of humor and problem-solving ability but also a family context that allows them to develop with a certain autonomy, not conformism, an optimistic vision of the future and a positive explanatory style in the face of complex situations (type of explanatory style) [60]. However, not all children with these characteristics develop high levels of resilience [58]. Some longitudinal empirical studies, such as one conducted by Reis, Colbert and Heber [62], analyzed the factors associated with resilience and its effects on academic performance in academically talented students and found that protective factors, such as having the support of significant adults, participation in varied extracurricular activities, high self-confidence and maintaining friendly relationships with peers, contributed to these students achieving high levels of performance in their academic lives. Moreover, positive emotions related to gratitude, hope, love and humor, among others, and their frequent expression in family contexts, constituted a string protective factor in students with high abilities who faced adverse situations in a resilient manner [63]. In addition, the locus of personal control, fostered by family figures, is key to resilience for students with high abilities, since it allows them to strengthen their levels of confidence, autonomy and coping with adverse situations that they perceive as challenging [64]. 
Regarding the association between high capacities, creativity and resilience, some research works have tried to explain their combination and effects. For instance, a research study with Brazilian high capacity adolescent students [65] focuses on psychological processes involved in identity, highlighting three dimensions: configurative (relate to identity); recursive (related to personal characteristics, resources and skills) and creative (linked to resilient factors, in which they gather a set of mechanisms responsible for exploring the various possibilities of dealing with the world, creating new combinations). In the sample of adolescents, significant correlations were found between the variables of self-concept (average), positive self-esteem, expectations and beliefs related to the locus of control, in relation to a high capacity for resilience; therefore, when adolescents with high intellectual abilities manifest positive self-concept and self-esteem, they perceive themselves as people with many psychological attributes and resources that are optimal for facing adverse situations. Although adolescents show heterogeneous profiles, identity is understood as a process resulting from the intersection between the organizational characteristics of the self, their relationships with others and their resilience, which generates positive expectations about the possibility of re-creating themselves.

Another more recent study [66] examined the variables associated with resilience, taking into account three domains: personal, parental and peer support, in Chinese middle school students with high academic abilities. The personal domain included variables such as hope, creativity and curiosity. In the parental support domain, trust, communication and parental alienation were considered; while in the peer support domain, trust, communication and peer alienation were analyzed. The results showed that the personal variables: hope, creativity and curiosity were related to the capacity of resilience of these students, while the parental support variables did not exhibit predictive effects superior to those of the personal variables and those corresponding to the peer support dimension had additional predictive effects.

In summary, while there is some consensus in the studies regarding personality features, intellectual abilities and family characteristics [67], high abilities are not synonymous with resilience; not all resilient children have high intellectual abilities, nor do all gifted children have resilient characteristics [16,68], hence the need to develop and implement proposals in different contexts, especially in school settings to promote resilience, focusing on analysis and action, individual and collective strengths which ensures the comprehensive development of students.

According to Dole [57] the main intervention strategies for resilience in students with high abilities, especially when it comes to double exception, are: (a) early identification and promotion of self-knowledge, crucial is the early identification of potential and difficulties; (b) targeted interventions, which need to focus not only on reducing risk factors in the lives of children and their family lives, but also on promoting the development of protective factors and activating resilient resources in the person and their contexts; (c)counseling, both for the student and his or her family, paying special attention to their emotional needs that must be addressed even before the academic aspects, strengthening links with significant people who provide unconditional acceptance; in this regard, self-knowledge is a necessary precursor to self-acceptance; (d) extra-curricular activities: enabling them to develop their skills positive self-esteem and self-efficacy, for instance, through artistic and creative activities.

For example, some intervention proposals, such as Ballam's [69], with highly skilled young people from indigenous ethnic groups in Oceania and in disadvantaged socio-economic circumstances, emphasize a sense of identity and supportive and affective relationships as essential factors in promoting resilience. Furthermore, in Mexico [70], following an ecosystem theory perspective, an intervention aimed at primary school students with high intellectual capacities, in an area of high social marginalization, highlighted the relevance of early identification of students' potential and the implementation of assessment and intervention programs that promote higher levels of resilience in the different school subsystems involved in their learning.

The importance of including activities that involve creative engagement has been highlighted in a number of intervention proposals related to resilience [71,72]. In this regard, Beghetto and Kaufman [73] 
have point out that, while people show creativity when they contribute something new that has value in the world (creativity as a "big C"), creativity is also an inherent part of everyday human experience. Therefore, involving people in activities that enable them to make new and valuable productions for their daily lives (creativity as a "small $C^{\prime \prime}$ ) is an optimal strategy for encouraging individual expression and strengthening social connections, hence the desirability of including creativity in proposals for intervention linked to resilience. For Beghetto [74], any practice related to creativity should consider the following issues: (a) teaching explicitly for creative thinking; (b) providing opportunities for choice and discovery; (c) encouraging students' intrinsic motivation; (d) establishing a learning environment that supports creativity; and, finally, (e) providing opportunities for students to use their imagination while learning.

In summary, resilience, creativity and high abilities are closely linked and a greater understanding of their characteristics and network of factors, at their different ecological levels of analysis, can be key to developing proposals for intervention in educational contexts. Therefore, the design, application and evaluative analysis of the contributions of an extracurricular intervention program in vulnerable school contexts, in order to develop resilience in students with high intellectual abilities would help to enrich not only the understanding of both issues: high abilities and resilience, but also to examine possible strategies to transform schools into resilient frameworks $[19,36]$.

Some young people with high capacities may be in contexts of high vulnerability and social risk, due to lack of development opportunities, living in contexts of economic and social marginalization, having a dysfunctional family and a disadvantaged social environment. Faced with this situation, it is necessary to develop their resilience to enable them to unfold their potential and thus overcome adversity.

Therefore, the objective of this paper is to describe an intervention program to promote the development of resilient factors in three cases of students with high intellectual abilities living in a marginalized urban area. Through this extracurricular enrichment intervention based on Grotberg's model [5,22], we sought to generate conditions of resilience that would make it possible to reduce the risk and vulnerability of the context of these students through their involvement in creative and meaningful activities that would be useful for them to explore, experiment, express their emotions and analytically contrast their own identity characteristics and their surrounding reality.

The following section describes the methodology followed by the case study. Subsequently, the results obtained in the three cases of students with high intellectual capacities are analyzed; and, finally, these results are discussed, and the conclusions and implications arising from the analysis of the intervention program and its contributions are pointed out.

\section{Materials and Method}

\subsection{Context and Setting}

The social context where this research was carried out is located in a municipality in the eastern region of Mexico City, which corresponds to the metropolitan and conurbation area of the Valley of Mexico, considered to be one of the municipalities with the highest degree of marginalization and insecurity in the Mexican Republic, with great contrasts within it. While most housing has basic services, urban infrastructure and services are deficient. According to the Statistical and Geographic Yearbook of Mexico City [75], this municipality has several unfavorable socioeconomic indicators (unemployment, low-paying jobs, and informal trade, among others); it was also noted as one of the most violent areas of the country. Education indicators show that nearly $3 \%$ of the population over the age of 15 is illiterate, and the average length of schooling was 9.6 years, with men exceeding women. Almost $20 \%$ of the population comes from other states of Mexico.

The intervention was carried out in a public middle school, located in this municipality, with which there have been previous collaborations. The school was founded 35 years ago. The middle school campus is composed of a total of 3 buildings of different levels. It has two sports courts, a library, 
a laboratory, and a multipurpose room. The school teaches in two shifts, morning and afternoon; the morning shift (in which the research was carried on), had 5 groups from each secondary school grade (15 in total), and serves approximately a ratio of 30 students per group (450 students in total). Most of the students come from this municipality. The school level of most parents is high school studies; only $10 \%$ have a bachelor's degree and another $10 \%$ have a postgraduate degree. With regard to economic activities, most mothers were housewives, without receiving financial remuneration; others were engaged in trade or ancillary work. Most fathers had a paid job in either in a formal or informal situation, working as traders, civil servants or in elementary or support activities. About school performance, one third of the students reported having failed at least one subject from the previous school year, such as Biology, Science, Geography and Mathematics. Most school absenteeism is reported as being due to illness or personal reasons.

\subsection{Design}

This is a comparative case study with a mixed methodological approach and an exploratory scope [76]. A concurrent triangulation design is used, since the collection and analysis of the quantitative and qualitative data was carried out at the same time as the implementation of the intervention program for the identified students [77].

\subsection{Participants}

The following criteria were used for the selection of the cases:

(a) Being diagnosed with high intellectual abilities

(b) Having studied at the same school since the 1st year of middle school

(c) Having a poor academic performance

(d) Having risk and vulnerability factor (family, economic, social)

The inclusion criteria were the following:

(a) Having the informed consent of their parents

(b) Having their consent to participate voluntarily during the program

(c) Attending $100 \%$ of the program

The study was carried out with three identified students with high intellectual capacities (one female and two male), from the second and third grade of middle school whose ages were between 13 and 14 years old.

The characteristics of the participants who met the inclusion criteria will be described below. To safeguard the students anonymity, their names were changed to fictitious ones.

Ana

Ana is 13 years old and in her second year of middle school. She lives with her parents. She has four brothers and sisters and she is the third child. Her mother was born in the state of Guerrero and currently has no paid job; she used to sell shoes. Her father is from Mexico City, he is a merchant; he sells chicken. She does not know her parents' level of education. As for her studies, Ana reports that she has been in school since pre-school; her average grade for the previous semester was 7.3 (out of 10), and she has failed two subjects during her studies: Physics and Ethics. In addition, she informs that she has had some unjustified absences during this school term (because of laziness).

Alberto

Alberto is 14 years old and in his third year of middle school. He lives with his parents; he is the youngest of three brothers, only one of whom lives in the family home. His mother was born in the state of Veracruz, did not finish her high school studies and currently does not have a paid job. His father is from Mexico City, did not finish his high school studies and currently works as a police 
officer. As for his studies, Alberto reports that he has been in school since pre-school; his average grade for the previous semester was 6 (out of 10), and he has failed three subjects during middle school: Mathematics, Workshop and Ethics. In addition, he says he has had some absences this school year due to illness.

Tomás

Tomás is 14 years old and in his third year of middle school. His parents are divorced, and he lives with his father and a younger sister. His father is a lawyer and we have no information about his mother. His average grade from the previous year is 7.5 and he has not failed any subjects; he likes Math and writing. He has had some absences during this term because of illness and other unjustified ones.

\subsection{Instruments and Materials}

\subsubsection{Instruments for the Identification of Students with High Abilities and Their Characterization}

1. Advanced Scale Progressive Matrix Test [78]. This is a psychometric test of perceptive intelligence that evaluates general non-verbal intelligence and analogical reasoning from a series of matrices arranged in different levels of increasing difficulty. It consists of two series, Series I consist of 12 problems, and allows training in the working method. Series II consist of 36 problems. It is applied collectively or individually; it allows examining high level educational capacity. It can be applied to people who stand out from the average and to adults. Those students who obtain a percentile equal or higher than 75 are selected.

2. Adolescent Academic Self-Concept Scale (AAPA) [79]. This is an academic self-concept scale for adolescent students with global dimensions. The scale has 16 Likert scale items with five levels of response: $1=$ Never, 2 = Sometimes, $3=$ Regularly, $4=$ Many times, $5=$ Always. They are grouped into 4 factors: self-regulation (before I start a task I analyze the different ways to carry it out), general intellectual skills (I analyze my grades to see if they correspond to what I did), motivation (I strive to make my work the best in the class) and creativity (to solve a problem, I look for ways that others would not think of). The test obtained a reliability of 0.828 through a Cronbach's alpha.

3. Torrance Creative Thinking Test TTCT-Figurative [80]. The objective of the Figurative TTCT is to evaluate creative productions through the composition of drawings. The productions resulting from these activities are evaluated in the following dimensions of creativity: Fluidity, Originality, Elaboration, Resistance to Premature Closure and Abstraction of Titles. The reliability coefficient for the creativity index is 0.985 .

4. Socio-demographic data sheet and evaluation of academic performance. This was an ad hoc questionnaire to find out the socio-demographic status of the participants and a brief academic history.

\subsubsection{Instruments for Evaluating Variables in Students}

1. Scale of Potential Resources for Adolescent Resilience (ERPRA by its Spanish acronym) [81]. This is a useful scale of measurement for assessing the potential resources that adolescents have for developing resilience at different levels (personal, family and social), and can be applied to teenagers aged 13-18 years. It is based on an ecological-trans-sectoral approach, where resilience is assumed to be a dynamic process in which various factors that mobilize in risk situations interact and result in positive adaptation. It is a questionnaire with 50 items, with 4 options of answer Likert style ( $1=$ Totally disagree; 2 = Disagree; $3=$ Agree; and $4=$ Totally agree). The factors are: (a) Positive thinking (14 items) is one of the factors that is most related to resilience, and it has reagents such as: if something worries me I concentrate on solving it, I think good things will happen to me. (b) Active coping (8 items) has reagents such as: I carry out my daily activities, even if I am going through a bad time. (c) Avoidance coping (8 items), with reagents 
such as: I prefer to keep my feelings to myself. (d) Family support (7 items), with reagents such as: I know I can count on my parents at any time. (e) Social support (4 items), with statements like: I think I can make friends easily. (f) Internal control—Self-control (3 items), with statements like: what happens to me in my life depends on my own actions. (g) Spirituality (3 items), with statements like: I feel that someone "up in heaven" is protecting me; and (h) External control (3 items), with statements like: when things don't work out for me, it's usually someone else's fault. The test has a Cronbach's alpha by a factor ranging from 0.642 to 0.746 (total alpha $=0.915$ ).

2. Abreaction Test to Evaluate Creativity (TAEC, by its Spanish acronym) Form B [82]. The TAEC is a graphic-inductive test to complete figures. Initially conceived to evaluate the control of the tension to the closing, it allows valuing also the factors of originality, elaboration, fantasy, connectivity, reach, expansion, expressive wealth. It allows evaluating creativity from different angles proposing categories that allow differentiating the subjects, and its application can be presented in a playful way. The test consists of 12 unfinished figures, presented on the same page and distributed in four rows and three columns in a symmetrical way. It has two forms that are applied pre-school-aged children (A) and another one to school-age children (B). A fixed time is not proposed to carry out the test for all the subjects; in this way, it is intended to favor individual rhythms and allows one to determine the creative style and the graphic fluency coefficient (the latter results from the sum of the scores in all the factors divided by the time used). It can be evaluated in a global way (low, medium, high); or in an analytical way, granting from 0 to 3 points to each figure of the test and in each factor according to the established criteria. The instruction for the creativity test is as follows: "Test your creativity. Draw a picture with these figures. Take the time you need and indicate when you finish".

It evaluates the following factors. (a) Delaying the closing of openings, without being carried away by the natural tension in order to immediately perceive an ending: this is the capacity to prolong the incubation period (time to think and solve a problem) that makes possible a potential to transform the environment and go beyond the information received. (b) Originality: the ability to give an unusual response, to produce ideas far from the obvious, from common, ordinary or established responses. (c) Elaboration: this test evaluates the details added to a given structure. (d) Fantasy: it is to go beyond the perceived images. Fantasy is lost with age and the demands of realism inherent in our school programs. (e) Connectivity: it is one of the most valid indicators of a person's creative potential. It is the ability to integrate superior graphic structures into a significant unit. (f) Imaginative scope. It is so called, because the subject imaginatively exceeds the graphic reagent and turns it into a pretext for a realization with a greater scope or projection. (g) Figurative Expansion: the result of breaking with the limits symbolically attributed to each figure. Both connectivity and expansion imply perceptive independence, tolerance to complexity, initiative and a certain degree of nonconformity. (h) Expressive wealth: expressive type factor. It refers to the dynamism, vivacity, coloring, contrasts of the composition. This test has an alpha of Cronbach of 0.80 and the standardized alpha value reaches 0.86

\subsubsection{Intervention Proposal: Enrichment Workshop to Develop Resilience from Creativity}

The components of the workshop are described below: the theoretical foundation, the objective, the methodological aspects, and the contents.

\section{(a) Theoretical basis}

The setting of secondary school students was chosen because it is an important stage in the life of a human being. Adolescence is an evolutionary stage marked by physiological, hormonal and psychological changes that generate tension between young people and their families $[83,84]$; adolescents are in search of their own identity, the meaning of life, and along with this, their interests, their needs for acceptance and belonging to their peer group, and the type of experiences to which they are exposed, among others, evolve. It is therefore important to address some factors that can contribute to their well-being and the shaping of their identity. 
At this stage of life, in spite of being exposed to adverse situations, it is possible to achieve a positive adaptation in the face of adversity, which has been described as the human being's capacity for resilience. As mentioned in the introduction, the study of resilience implies a change in the perception of the individual, based on potentialities, resources and in relation to his or her environment, which implies the interaction of different personal, family and social factors [81].

In education, resilience plays an important role, since by promoting it, the development of social, academic and personal skills can be fostered, allowing the student to overcome adverse situations and move forward in life [11]. An interesting way to promote resilience factors is through creativity [35].

In the words of Torrance [85], "creativity is a process that makes someone sensitive to problems, deficiencies, cracks or gaps in knowledge and leads them to identify difficulties, seek solutions, speculate or formulate hypotheses, test and verify those hypotheses, modify them if necessary, and communicate the results". It can also be defined as an ability to produce work that is both novel (original, unexpected) and appropriate (useful, adaptive) [30]. The concept is closely related to individual levels (cognitive and motivational processes) and social levels (contextual influences) of productive activity. For example, at an individual level, creativity is relevant to the solution of professional or everyday problems [35,86-88]; whereas, at a social level, creativity may lead to scientific discoveries, new inventions, and the creation of new products or services $[30,89]$. These qualities are associated with students with high intellectual abilities.

From Renzulli's theory [90], the characteristic features of a creative person are: originality of thought, openness to experience, novelty of approach, ability to leave established conventions, curiosity, speculation, desire to take risks and the uniqueness of a person's contribution or innovation. In addition to these traits, the studies that have been carried out in order to understand the creative process raise the need to pay more attention to aspects such as personality, talent, culture, cognition, the characteristics of the task and other issues that influence this process [91,92], but above all, to point out the great weight of motivation and love for one's work in order to achieve a creative product.

The workshop program is based on Grotberg's resilience model [22] and on the potential resources for resilience in adolescents by Barcelata and Rodríguez [81,93]. Grotberg establishes three specific areas that when interacting with each other can generate resilient behaviors; Barcelata and Rodríguez some resources that can be associated with these areas. Consequently, one of the areas responds to internal strengths (I am), can be associated with active coping and spirituality; external support and resources (I have) are associated with family support and social support; and interpersonal and social skills (I can) are related to positive thinking and self-control. The workshop tries to have an impact some factors such as self-knowledge-identity, positive thinking, empathy, flexibility, optimism, social skills, the acquisition of coping strategies and the recognition and expression of emotions in their protective function [94].

In turn, the program assumes some principles for the achievement of creative potential, taking into account personal and cultural components: (a) motives: to be creative and the belief that oneself can become creative; (b) means: necessary skills and appropriate knowledge; (c) opportunities: awareness of potential opportunities, creating the opportunities, dealing with the pressures against creativity. For the training of creative potential, the model based on the four " $\mathrm{C}^{\prime} \mathrm{s}$ " of creativity from Helfand et al. [87] is chosen, particularly the so-called little c, which contributes to solving everyday problems. Likewise, the strategies proposed by Betancourt [95] are used to generate a creative atmosphere that tries to eliminate the blockers of creativity such as envy, jealousy, competition, guilt, perfectionism, and value judgments, among others [96].

\section{(b) Objective}

The aim of the workshop is to promote the development of intrinsic protective factors in students with high abilities in disadvantaged social environments, which can reduce the risk and vulnerability of their context by involving them in creative and meaningful activities for the group that allow them to explore, experiment and contrast reality. By developing creativity, in addition to gaining greater 
sensitivity to problems, the student will be able to develop a wider range of possible solutions to those problems, which is why it is considered that protective factors will increase. In turn, the increase of protective factors will contribute to the promotion of creativity.

(c) Methodological aspects

The design of the program was structured under the following key elements:

- Educational devices. Some tools that have proven to be effective for the development of creativity and at the same time as protective factors to overcome adversity, are art, writing, play and dramatizations. These tools have served as a thread for the exploration of creative potential, identity, emotions, communication processes and cooperation among equals, through personal and group production and reflection [96-100].

- Constant variables: for group cohesion and identity, four variables were maintained [101]: (a) constancy in relation to the person directing the intervention, that is, the mediator of the sessions must always be the same so that situations do not arise that, instead of favoring the work climate, hinder or inhibit it. (b) Constancy in space and time. The experience should be carried out on the same day, in the same weekly schedule and in the same physical space that allows for different ways of organizing the group. (c) Constancy in the structure and sequence of the sessions. In the case of an unforeseen event, a difficulty or the group requires it, the structure of the sessions will be modified. (d) Consistency in terms of duration per session.

- Structure of the sessions: the workshop consists of five moments: group dynamics (activities or games for group cohesion); presentation of the objectives; development of the activities (sometimes an explanation, a trigger question, followed by the activity or activities), final reflection and evaluation. The sessions are structured around a general theme, from which different mediating activities are derived in order to achieve the aims of the program. In all sessions, one or two products were produced.

- Timing: the workshop consisted of 9 face-to-face work sessions lasting $90 \mathrm{~min}$; two of which were used for the initial evaluation (framing) and final evaluation. They were held twice a week (Monday and Thursday).

- Working method: we tried to combine individual and group work, in order to establish a creative atmosphere, which would allow for genuine cooperation and a sense of belonging.

- Workshop materials: a variety of materials were used, both technological (projector and computer) and school materials: blank sheets, printed sheets, pens, newsprint, tape, colored sheets, glue, scissors, balloons, etc.

- Pedagogical aspects: the role of the mediator starts from the moment he selects, organizes, groups and structures those stimuli in the environment that will be sufficiently problematic to start the cognitive conflict that will generate in the participants the need to think and put their skills into practice. In the case of this workshop, in addition to the main researcher, there was a student who was in his second year of a bachelor's degree in Psychology who had the role of supporting instructor and observer of the dynamics that were generated. The role of the student is assumed to be active, responsible, proactive and cooperative.

- Evaluation: in each session, the products were evaluated based on the skills trained according to the Grotberg model [94]; in addition, three aspects were evaluated through a questionnaire: what they liked/disliked most, what they learned and suggestions for improvement. At the end of the workshop, an ad hoc satisfaction questionnaire was applied that consisted of 11 closed items that evaluated: level of general satisfaction with the workshop, level of learning, level of satisfaction with the facilities, level of satisfaction with the instructors, level of satisfaction with the contents and materials. There were also some open-ended questions to explore in more detail what they liked best, what they liked least, what they learned, and how they would improve the workshop. 
(d) Contents:

The topics addressed during the workshop had a progression, ranging from self-knowledge to skills needed to interact with others. Table 1 details the content of the workshop, as well as the objectives, activities and resilient areas.

Table 1. Contents, objectives and activities of the creativity and resilience workshop.

\begin{tabular}{|c|c|c|c|c|c|}
\hline & Theme & Objective & Activities & Resilient Area & Potential Resources \\
\hline 1. & $\begin{array}{l}\text { Frame of } \\
\text { the workshop }\end{array}$ & $\begin{array}{l}\text { The student will reflect on his or her } \\
\text { own creative processes by taking a } \\
\text { graphic test of creativity and answering } \\
\text { a questionnaire on resilience factors. }\end{array}$ & $\begin{array}{l}\text { - Presentation } \\
\text { Application of TAEC } \\
\text { and ERPRA }\end{array}$ & $\begin{array}{l}\text { I am } \\
\text { I can } \\
\text { I have }\end{array}$ & \\
\hline 2. & I'm creative & $\begin{array}{l}\text { The student will activate and reflect on } \\
\text { different divergent thinking processes } \\
\text { for the elaboration of products, } \\
\text { recognizing his/her own abilities. }\end{array}$ & 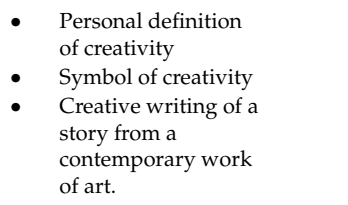 & I am & Active Coping \\
\hline 3. & My identity & $\begin{array}{l}\text { The student will understand the } \\
\text { concept of identity and define the } \\
\text { features that make up their identity by } \\
\text { exhibiting works by contemporary } \\
\text { artists and making a product that } \\
\text { reflects their identity. }\end{array}$ & $\begin{array}{l}\text { The identity from } \\
\text { contemporary art: elaboration } \\
\text { of a self-Portrait }\end{array}$ & I am & Active Coping \\
\hline 4. & Feelings & $\begin{array}{l}\text { The student will experience and study } \\
\text { the changes in emotional behavior, } \\
\text { which color and its forms of application } \\
\text { have on behavior and mood itself. }\end{array}$ & Our feelings have color & I am & $\begin{array}{l}\text { Active Coping } \\
\text { Spirituality }\end{array}$ \\
\hline 5. & $\begin{array}{l}\text { Creative and } \\
\text { cooperative games }\end{array}$ & $\begin{array}{l}\text { The student will participate in various } \\
\text { games in which he or she will have to } \\
\text { display a series of social skills } \\
\text { important for cooperative work }\end{array}$ & $\begin{array}{ll}- & \text { Paper wheel } \\
\text { - } & \text { Playground games } \\
\text { - } & \text { Exquisite corpse }\end{array}$ & $\begin{array}{l}\text { I can } \\
\text { I have }\end{array}$ & $\begin{array}{c}\text { Internal control } \\
\text { Positive thinking Socia } \\
\text { Support }\end{array}$ \\
\hline 6. & $\begin{array}{l}\text { Self-image } \\
\text { and self-knowledge }\end{array}$ & $\begin{array}{l}\text { The student will participate in activities } \\
\text { to improve understanding of each other, } \\
\text { promoting empathy and mutual help. }\end{array}$ & $\begin{array}{l}\text { - } \quad \text { Today in the life of ... } \\
\text { Writing } \\
\text { - } \quad \text { Dour autobiography } \\
\text { Dynamics: I would like } \\
\text { to overcome, I regret, A } \\
\text { problem of mine is ... }\end{array}$ & $\begin{array}{l}\text { I am } \\
\text { I have }\end{array}$ & $\begin{array}{l}\text { Active coping Social } \\
\text { Support }\end{array}$ \\
\hline 7. & Resilience 1: factors & $\begin{array}{l}\text { The student will understand the } \\
\text { influence of protective factors and risk } \\
\text { factors on the development of resilience. }\end{array}$ & $\begin{array}{l}\text { Games to differentiate } \\
\text { protective factors } \\
\text { (personal, family, school } \\
\text { and social) and risk } \\
\text { factors (individual, } \\
\text { interpersonal, environmental) }\end{array}$ & $\begin{array}{l}\text { I am } \\
\text { I have }\end{array}$ & $\begin{array}{c}\text { Active coping, Social } \\
\text { Support }\end{array}$ \\
\hline 8. & $\begin{array}{l}\text { Resilience 2: } \\
\text { coping strategies }\end{array}$ & $\begin{array}{l}\text { The students will be presented in an } \\
\text { extreme situation, in which they will } \\
\text { learn to respect decisions and manage } \\
\text { their emotions. }\end{array}$ & $\begin{array}{l}\text { Dynamics to evaluate } \\
\text { their coping strategies, } \\
\text { decision making and } \\
\text { emotional management. } \\
\text { Problem-centered, } \\
\text { emotion-focused strategies }\end{array}$ & $\begin{array}{l}\text { I can } \\
\text { I have }\end{array}$ & $\begin{array}{c}\text { Internal control } \\
\text { Positive thinking Socia } \\
\text { Support }\end{array}$ \\
\hline 9. & $\begin{array}{l}\text { Resilience 3: } \\
\text { collaborative work }\end{array}$ & $\begin{array}{l}\text { The student will participate in a series } \\
\text { of dynamics to promote understanding } \\
\text { of putting their interpersonal skills at } \\
\text { the service of a common goal. }\end{array}$ & $\begin{array}{ll}\text { - } & \text { Dynamics for collective } \\
\text { problem solving } \\
\text { - } & \text { Workshop closure } \\
\text { Application of TAEC } \\
\text { and ERPRA } \\
\text { - } \begin{array}{l}\text { General evaluation of } \\
\text { the workshop }\end{array}\end{array}$ & I can & $\begin{array}{l}\text { Internal control } \\
\text { Positive thinking, }\end{array}$ \\
\hline
\end{tabular}

\subsection{Procedure}

The identification of students with high abilities was done at the beginning of the 2017-2018 school year; the informed consent of both the authorities of the middle school and the teachers of the groups, as well as of the participants who were in their classrooms with their subject teacher was requested. The applying was done in a two-hour session. At the beginning they were given a brief explanation of 
the purpose and importance of completing the questionnaires and were asked to accept them. They were then given the two Series I and II booklets of the Advanced MPA Scale as well as the answer sheet, and then followed the instructions given by the Manual for Progressive Matrixes Advanced Scale Test [78]. At the end of the $40 \mathrm{~min}$ they were asked to answer the Academic Self-Concept Scale [79], which lasts approximately $15 \mathrm{~min}$. Finally, they were given the Thinking Creatively with Drawing booklet, the TTCT-Figural test that consists of three activities: building drawings, finishing drawings, and finally, lines. At all times, the rules of application of the Torrance test were followed [80], offering precise instructions and considering, as the author points out, the application times for each subtest, that is, $10 \mathrm{~min}$ for each activity, making a total of $30 \mathrm{~min}$. The psychological climate before and during the administration of the test was intended to be comfortable and stimulating.

Data from the study were captured in the SPSS 19 software, evaluated and statistically analyzed. In order to identify adolescents with outstanding skills, the minimum and maximum scores obtained by the population were considered. For identification, the 75th percentile $[102,103]$ for intellectual capacity was taken as the cut-off point, and the same percentile in at least one of the other two intrinsic characteristics. Overall, 251 students were evaluated and 22 with outstanding abilities were identified.

During the 2018-2019 school year, a new informative meeting was held with the school's Assistant Principal, to present the enrichment workshop and request her support to carry it out with the students detected with high abilities. Through her, informed consents were given and signed by parents interested in having their children participate in the project; likewise, the students summoned were told that the activity was voluntary. At first, there were five students, but only three students attended $100 \%$ of the sessions.

The enrichment program was implemented in nine 90-min sessions during the months of April and May 2019 (on Mondays and Thursdays), within the schedule established by the school's management. In the first session, the presentation and framing of the workshop took place. Some integration dynamics were carried out and the TAEC and ERPRA tests were applied. The following eight sessions were carried out as planned. In the ninth session, the creativity and resilience tests were applied again, as well as a questionnaire to assess the satisfaction of the workshop.

\subsection{Data Analysis}

For the analysis of quantitative data, given the small number of study participants, the Wilcoxon non-parametric signed rank test was used with the SPSS version 19 software for Windows. For the qualitative analysis, the sessions are grouped by skills (I am, I have, I can), and the analysis is done on some products derived from the sessions, which best exemplify the process of appropriation of the trained skills.

\section{Results}

The purpose of this research is to find out not only the results of the intervention but also how the process develops in each of the participating adolescents, collecting data from the tests applied and the products made during the workshop. In this intervention experience, we worked mainly on the individual factors of recognition of their abilities and their support in facing adversity; however, we were also able to analyze family, school and emerging social factors.

Before moving onto the analysis itself, we presented the characterization of the students, based on the data obtained from the socio-demographic questionnaire and the analysis of the context.

Ana

Ana was identified with high abilities in the first year of middle school; she has many friends with whom she enjoys going out and feels identified, which can be considered as protective factors; nevertheless, she has several risk factors, such as birth order (she is the third of four siblings), low academic performance, lack of motivation in school and, according to school counselors, she seems to be lazy and irresponsible, as she acknowledges. Other family and school risk factors are low 
income and low-level education from her parents, the school's location in an area of drug trafficking, insecurity and gangs' formation. In Ana's case, risk factors are considerably more important than protective factors. During the first workshop sessions she seemed a bit distracted and wary, despite her participation in the activities.

Alberto

Alberto was identified with high abilities when he was studying the second year of middle school. As with Ana's case, this has been a protective factor. As risk factors we found poor school performance and failure in several classes; the guidance counselor comment that Alberto is a rather quiet student and has difficulties engaging in social activities; additionally, his family's economic situation and his parents' low education may yield low expectations of their son's progression; Alberto's school location and context may also be an adverse factor for him.

During the sessions, Alberto was extremely shy, as if he as if he wanted to be unnoticed, however, he seemed to be attentive to the instructions. Despite his low performance, he seemed responsible, involved and cooperative in the activities.

Tomás

Tomás was identified with high abilities when he was studying the second year of middle school. As in the previous cases, this was a protective factor. As risk factors, he reports to have an average school performance; counselors report that Tomás thinks highly of himself; his parents are separated (he lives with his father); his father's education level is higher than the average of other school parents and the economic situation is regarded as middle-low income. Some family conditions and the school context could be adverse factors for his development.

During the sessions, Tomás showed himself as extroverted, cheerful and jolly; however, he often demanded the attention of an adult by interrupting the flow of the activities. Despite this, he always collaborated in the activities and lightened the mood. He was notoriously worried about getting the required grades in Mathematics in order to join his high school of choice.

According to the data obtained from the socio-demographic questionnaire and data provided by their Schools Principal, some risk and protective factors were detected and thus led the intervention. Table 2 summarizes the risk and protective factors detected in the three students.

Table 2. Risk and protective factors of participants.

\begin{tabular}{|c|c|c|c|c|c|c|c|}
\hline \multicolumn{4}{|c|}{ Risk Factors } & \multicolumn{4}{|c|}{ Protective Factors } \\
\hline Characteristics & Family Risk & School Risk & Social Risk & Characteristics & Family Support & School Support & Social Support \\
\hline $\begin{array}{l}\text { High ability } \\
\text { Low } \\
\text { self-esteem } \\
\text { Lack of school } \\
\text { motivation } \\
\text { Order of birth } \\
\text { Adolescence }\end{array}$ & $\begin{array}{l}\text { Low economic } \\
\text { and educational } \\
\text { level } \\
\text { Parent's } \\
\text { occupation } \\
\text { Lack of role } \\
\text { models } \\
\text { Lack of family } \\
\text { and emotional } \\
\text { support } \\
\text { Divorced } \\
\text { parents }\end{array}$ & $\begin{array}{c}\text { Low } \\
\text { expectations } \\
\text { Low } \\
\text { performance } \\
\text { Failing } \\
\text { subjects } \\
\text { Absenteeism } \\
\text { Low valuation } \\
\text { of their } \\
\text { capacities } \\
\text { Some teachers }\end{array}$ & $\begin{array}{l}\text { Living in an } \\
\text { area of high } \\
\text { economic and } \\
\text { social } \\
\text { deprivation } \\
\text { Being exposed } \\
\text { to alcoholism }\end{array}$ & $\begin{array}{l}\text { High ability } \\
\text { Humor } \\
\text { Good health }\end{array}$ & $\begin{array}{l}\text { Family support } \\
\text { Models to be } \\
\text { followed }\end{array}$ & $\begin{array}{l}\text { Communication } \\
\text { They have } \\
\text { school } \\
\text { counselors } \\
\text { Principal's } \\
\text { support } \\
\text { Identification of } \\
\text { high capacities } \\
\text { Openness to } \\
\text { enrichment } \\
\text { programs }\end{array}$ & Friends \\
\hline
\end{tabular}

Even though high ability may become a protective factor in students, when the environment in which they are immersed does not recognize, value and promote talent, the growth of their potential may be diminished and translated into a feeling of inadequacy, low self-esteem, low school motivation, thus resulting in poor academic achievements, as it was the case with some of the participants. Some family and social aspects, such as economic situation, parents' level of education and occupation in an underprivileged context could contribute to the low expectations towards these students. However, despite such adverse conditions, personal characteristics are also at play, along with other family and social features that can provide support and guidance towards their development. This 
research was interested in having an influence in school factors by proposing a set of strategies to enable social connections between mentors and schoolmates to facilitate resilient conducts that have been already documented for students with high abilities [104].

In the following section we show the quantitative results from the test application; afterwards, we present the qualitative evaluation derived from the student's products.

\subsection{Quantitative Results}

Regarding the data from the Scale of Potential Resources for Resilience for adolescents (ERPRA) [81], we could observe, by employing the Wilcoxon test that there are no statistically significant differences between scores from before and after the educational intervention (Table 3), that is, for positive thinking $(z=-1.07, p>0.05)$, active coping $(z=-1.63, p>0.05)$, avoidance coping $(z=-1.34, p>0.05)$, family support $(z=-0.535, p>0.05)$, social support $(z=-0.48, p>0.05)$, internal control $(z=-0.72, p>0.05)$, spirituality $(\mathrm{z}=-1.69, p>0.05)$, and external control $(\mathrm{z}=0.01, p>0.05)$. In Table 3 we show the median and standard deviations pre-test-post-test, and in Table 4 pre-test post-test scores are observed for each participant.

Table 3. Descriptive of the Scale of Potential Resources for Resilience for adolescents (ERPRA). $n=3$.

\begin{tabular}{|c|c|c|c|c|}
\hline \multirow[b]{2}{*}{ Factors } & \multicolumn{2}{|r|}{ Pre-Test } & \multicolumn{2}{|r|}{ Post-Test } \\
\hline & Median & Standard Deviation & Median & Standard Deviation \\
\hline 1. Positive thinking & 2.64 & 0.21822 & 3.14 & 0.45922 \\
\hline 2. Active coping & 2.75 & 0.26021 & 2.88 & 0.12500 \\
\hline 3. Avoidance coping & 2.38 & 0.50518 & 3.13 & 0.43301 \\
\hline 4. Family support & 2.43 & 0.50518 & 2.86 & 0.74231 \\
\hline 5. Social support & 2.75 & 0.72169 & 3.00 & 0.2500 \\
\hline 6. Internal control & 3.00 & 0.66667 & 3.33 & 0.38490 \\
\hline 7. Spirituality & 3.00 & 1.15470 & 1.67 & 0.33333 \\
\hline 8. External control & 3.00 & 1.26198 & 2.67 & 0.33333 \\
\hline
\end{tabular}

Table 4. Mean scores per participant in the pre-test-post-test of the Potential Resources for Resilience scale for adolescents (ERPRA).

\begin{tabular}{llcccccc}
\hline & & \multicolumn{2}{c}{ Ana } & \multicolumn{2}{c}{ Alberto } & \multicolumn{2}{c}{ Tomás } \\
\cline { 3 - 8 } & \multicolumn{1}{c}{ Factors } & Pre & Post & Pre & Post & Pre & Post \\
\hline 1. & Positive thinking & 2.71 & 2.43 & 2.64 & 3.29 & 2.36 & 3.14 \\
2. & Active coping & 3.50 & 2.88 & 2.88 & 3.00 & 2.38 & 2.75 \\
3. & Avoidance copin & 2.25 & 3.13 & 2.38 & 2.38 & 2.75 & 3.13 \\
4. & Family support & 1.86 & 1.57 & 2.43 & 2.86 & 1.43 & 2.86 \\
5. & Social support & 3.25 & 3.00 & 2.75 & 3.25 & 2.75 & 2.75 \\
6. & Internal control & 2.67 & 2.67 & 3.00 & 3.33 & 2.33 & 3.33 \\
7. & Spirituality & 2.00 & 1.67 & 3.00 & 3.00 & 1.00 & 1.33 \\
8. & External control & 2.33 & 3.00 & 3.00 & 2.33 & 3.33 & 2.67 \\
\hline
\end{tabular}

To the qualitative pre-test question "Which are your attributes and strengths that enable you to cope with difficult situations?" Ana answered: "talking or getting drunk". To the same question in the posttest she answered: "being patient". In the pre-test, Alberto did not answer and in the posttest, he wrote "I make lot of friends, I am kind". Lastly, Tomás wrote in the pre-test: "crying, bringing out what's inside of me", and in the posttest: "being realist, fair and seeing if there is a solution".

Even if the objective of this research was not necessarily to enhance the creativity of the participants, but to use creative strategies to modulate resilience factors, some indicators of that sort of potential were evaluated as a starting point. The Abreaction Test to Evaluate Creativity TAEC [82] was applied. By means of the Wilcoxon there were no differences regarding resistance to closure $(z=-0.45, p>0.05)$, originality $(\mathrm{z}=-0.82, p>0.05)$, elaboration $(\mathrm{z}=-1.34, p>0.05)$, fantasy $(\mathrm{z}=-1.34, p>0.05)$, connectivity $(\mathrm{z}=-1.00, p>0.05)$, nor imaginative scope $(\mathrm{z}=-1.34, p>0.05)$. Even though the quantitative results do not present differences, when a detailed qualitative analysis is carried out some changes are 
apparent, as shown below. In Table 5, the Median and Standard deviations pre-test-post-test are shown, and Table 6 presents direct scores and percentiles for each one of the participants.

Table 5. Descriptives of the pre-test and post-test Creative Abreaction Test (TAEC). $n=3$.

\begin{tabular}{ccccc}
\hline & \multicolumn{2}{c}{ Pre-Test } & \multicolumn{2}{c}{ Post-Test } \\
\cline { 2 - 5 } Factors & Median & Standard Deviation & Median & Standard Deviation \\
\hline Time spent (minutes) & 9.10 & 1.415 & 10.00 & 1.527 \\
Resistance to Closure & 17.00 & 4.583 & 20.00 & 1.732 \\
Originality & 11.00 & 4.619 & 13.00 & 7.234 \\
Elaboration & 3.00 & 3.606 & 5.00 & 3.00 \\
Fantasy & 0.00 & 3.464 & 1.00 & 4.359 \\
Connectivity & 0.00 & 0.00 & 0.00 & 0.00 \\
Imaginative scope & 4.00 & 2.646 & 5.00 & 7.638 \\
Figurative Expansion & 7.00 & 6.807 & 6.00 & 13.077 \\
Expressive richness & 4.00 & 1.528 & 10.00 & 2.082 \\
Graphical flow coefficient & 4.27 & 2.505 & 5.60 & 2.848 \\
\hline
\end{tabular}

Table 6. Direct and percentile scores by participants of the Creative Abreaction Test (TAEC). Pre-test and post-test measures.

\begin{tabular}{|c|c|c|c|c|c|c|c|c|c|c|c|c|c|}
\hline \multirow[b]{2}{*}{ Factors } & \multirow[b]{2}{*}{ Max Points } & \multicolumn{4}{|c|}{ Ana } & \multicolumn{4}{|c|}{ Alberto } & \multicolumn{4}{|c|}{ Tomás } \\
\hline & & Pre & PC & Post & PC & Pre & PC & Post & PC & Pre & PC & Post & PC \\
\hline Time spent (minutes) & & 7.48 & - & 8 & - & 10.30 & - & 10 & - & 9.10 & - & 11 & - \\
\hline Resistance to Premature Closure & 36 & 17 & 60 & 17 & 60 & 14 & 40 & 20 & 75 & 23 & 90 & 20 & 75 \\
\hline Originality & 36 & 3 & 10 & 1 & 5 & 11 & 45 & 13 & 60 & 11 & 45 & 14 & 65 \\
\hline Elaboration & 36 & 1 & 5 & 2 & 5 & 3 & 10 & 5 & 20 & 8 & 45 & 8 & 45 \\
\hline Fantasy & 36 & 0 & - & 1 & 15 & 0 & - & 0 & - & 6 & 60 & 8 & 70 \\
\hline Connectivity & 36 & 0 & - & 0 & - & 0 & - & 0 & - & 0 & - & 6 & $*$ \\
\hline Imaginative scope & 36 & 0 & - & 0 & - & 4 & 10 & 5 & 15 & 5 & 15 & 15 & 65 \\
\hline Figurative Expansion & 36 & 7 & 15 & 3 & 5 & 4 & 5 & 6 & 10 & 17 & 60 & 27 & 95 \\
\hline Expressive richness & 36 & 4 & 15 & 11 & 85 & 3 & 10 & 7 & 35 & 6 & 30 & 10 & 75 \\
\hline Graphical flow coefficient & & 4.27 & 50 & 4.38 & 55 & 3.79 & 40 & 5.6 & 65 & 8.35 & 80 & 9.81 & 85 \\
\hline
\end{tabular}

* There's no scale on the test for Connectivity.

The following are the protocols of the TAEC of the pre-test and the post-test of all the participants. In the case of the first participant (Figure 1), it can be noted that despite no significant changes in most of the factors of creativity, Ana shows a higher than average percentile in resistance to closure, which does not necessarily indicate productive creativity, but a potential to transform the environment and customize it. In addition, she increased her scores on the expressive richness factor, which emphasizes communicative expression, shows colorfulness and dynamic. The difficulty to increase her scores in the rest of factors or indicators is probably mediated by the conditions of her context that do not allow her to expand, recreate, and leave behind fears that block creativity.

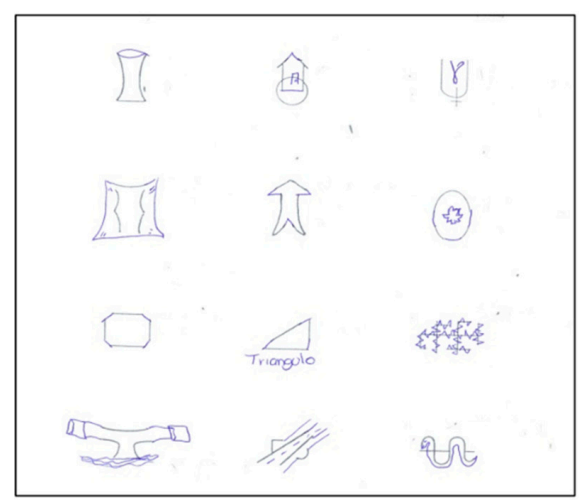

Ana pre

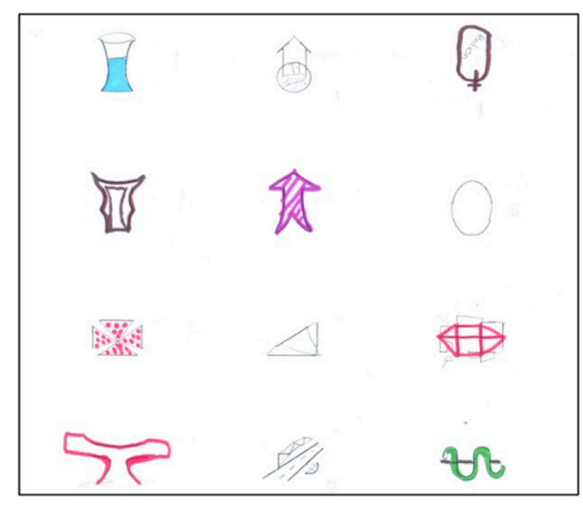

Ana post

Figure 1. Protocols of the TAEC pre-test-post-test of Ana. 
With regard to Alberto's scores, percentiles can be seen well below the normative average in all factors of the TAEC at the beginning of the workshop. However, after the intervention he managed to modestly increase all his scores, which include resistance to closure and originality (see Figure 2).

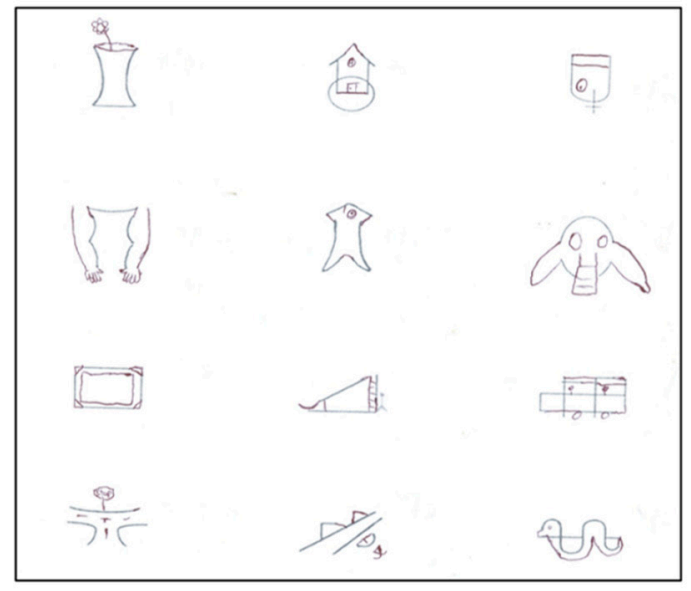

Alberto pre

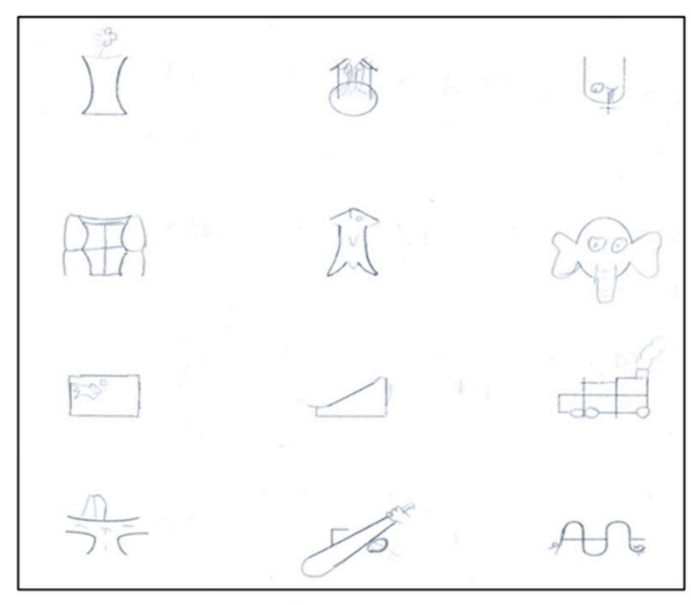

Alberto post

Figure 2. Protocols of the TAEC pre-test-post-test of Alberto.

Finally, Tomás' scores were generally higher than the rest of his peers at the beginning of the intervention and even increased after the intervention. Although he decreased his scores for resistance to closure, other indicators showed a significant increase, such as imaginative scope, fantasy, figurative expansion and expressive richness; it can be seen that these last two factors respond more to an attitude of facing risks, of exceeding the given limits; a need for expansion of feelings and communication (see Figure 3).

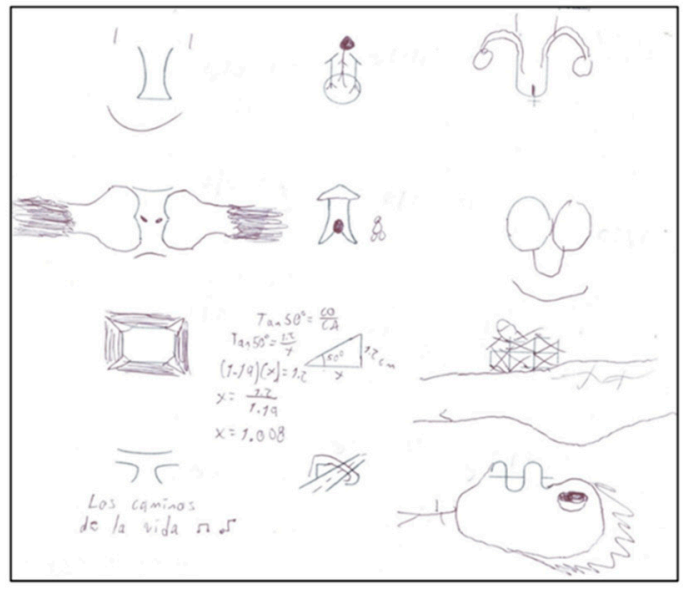

Tomas pre

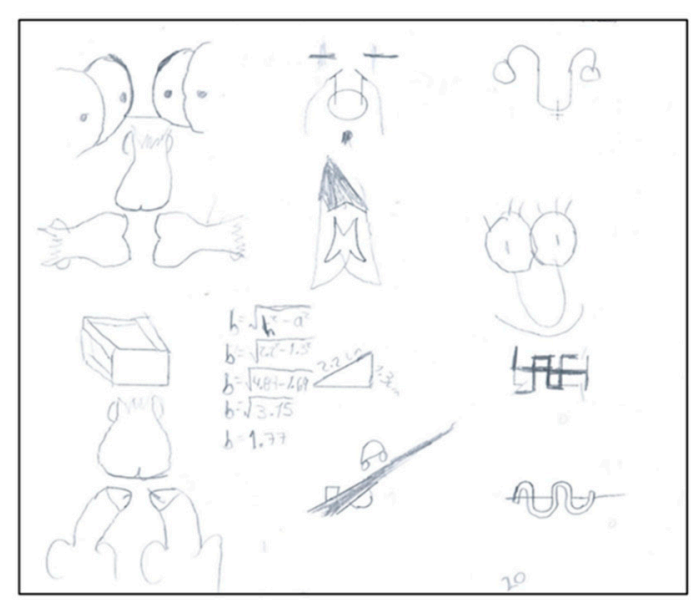

Tomas post

Figure 3. Protocols of the TAEC pre-test-post-test of Tomás.

\subsection{Qualitative Results}

Here, we present the qualitative results from the intervention. The analysis is carried out case by case, taking the most significant students' products during the workshop as the guiding threads. The analysis is performed by using Grotberg's abilities scheme [94] I am (sessions 2, 3 and 4), I have (sessions 5, 6 and 7), I can (sessions 8 and 9). 


\subsubsection{Productions by Ana}

Results from the Program on Inner Strength Aspect (I Am -Active Coping and Spirituality)

In this section we seek to analyze aspects related to autonomy, satisfaction, self-valuation of sentiments of achievements, and coping. One of the first activities was drawing a symbol that represented creativity. Figure 4 shows Ana's product.

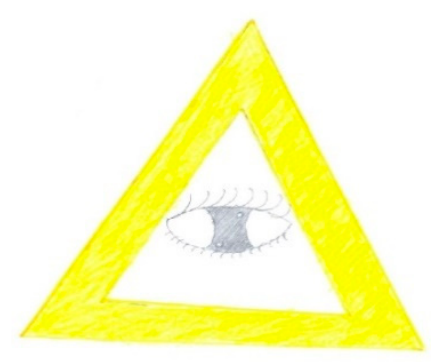

Figure 4. Symbol of Ana's creativity.

Ana's drawing is a yellow triangle with an open eye at the center. The shape (triangle) and color (yellow) used by the student can be associated to features of high conscience or self-conscience and her intelligence, but also may reflect some anger. For her, creativity is "An art". She does not explain in detail the meaning of her symbol, she simply states that "... I drew this picture because nothing else occurred to me".

Another activity that implied letting imagination flow, making her thoughts more flexible and projecting her feelings and giving them meaning could be achieved with creative writing. She was asked to write a tale inspired on some images of the surrealist Belgian painter René Magritte. For Ana, the painting was "The son of man" (1964). She wrote:

"The past of a weird man"

There was a man that always had his face covered with an apple and everyone thought he was a weird man; one day he called the news show because he did not take the apple off.

He explained the reason why he always had it. He said:

-"I always have that apple because I have a past and such past hurt me so much, I want to cover my face because I do not want to see the other side, I am a very closed person and that is also why I have that apple, as there is so much to be told".

He left crying, tears running down his face, because in that moment he remembered all that had happened.

He had already vented his sorrows, so he decided to uncover his face and carry on with his life and remember nothing.

The end.

In an act of introspection, Ana seems to recognize, at least in the fiction of the story, that there are things that hurt her, but she knows that being able to express them, tell them to someone and even cry, can be liberating and restorative. Her coping strategies are activated.

Another part of the workshop was to work on aspects of her identity and self-knowledge. In this session, we used art as a mediator. At the beginning of the activity they were asked what they understood by identity; afterwards a brief conceptual explanation was given. Then, some contemporary art paintings were presented, whose thematic axis was self-portraits. The works presented were by Vick Muníz, Francis Bacon, Frida Kahlo, Carmen F. Sigler, Estíbaliz Sádaba and Ana Mendieta. At the end of the exhibition of each artist, they were asked how they imagined each one of them in person and what they thought they wanted to transmit with their works. Finally, they were asked: "How would 
you express your own identity?". The exercise consisted in making a self-portrait with the technique, materials, form and texture that they liked best, or that they had noticed or wanted to experiment with. Figure 5 shows Ana's self-portrait.

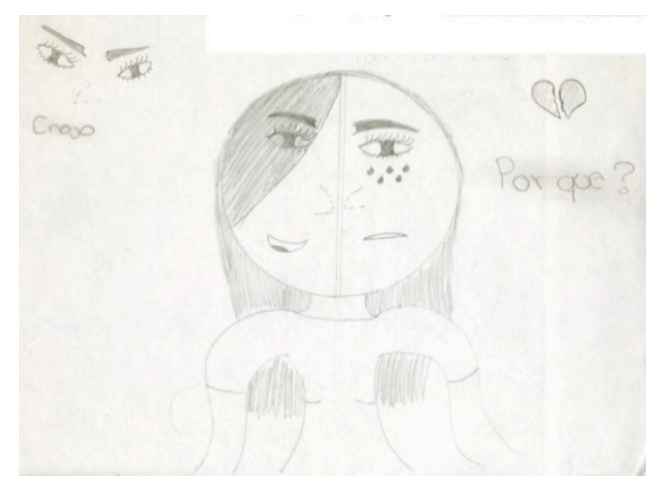

Figure 5. Ana's self-portrait.

As can be seen, Ana's self-portrait has chiaroscuro and a contradictory representation of herself between happy and sad, even drawing on the left side of the main figure an angry expression in her eyes. Additionally, she adds a broken heart on the extreme right, with an existential question: why?

Program Results on External Support Factor (I Have -Family Support and Social Support)

In this section we are interested in analyzing the goals, sense of action, interpersonal, family and social ties and networks, and affective judgments.

After some sessions about identity, self-knowledge, recognition of emotions, and after having presented them with the biography of some famous people who had to face great adversities like Victor Frankl, they were invited to write their own autobiography.

This is how Ana defines herself as a rebellious, rude girl who never pays attention, likes to be on the street, likes to relax, go out with her friends and do bad things; she says she hates studying but wants to be someone in life. She wants to get easy things, but she doesn't have them. She accepts that she likes to drink. When she grows up, she wants to have everything she wants, but that is by working. She also says she wants to have a long life with the partner she loves. When asked if she had a role model, she said she would like to be a singer like Bad Bunny (a Puerto Rican rapper) and be like them.

Results from the Program on Interpersonal and Conflict Resolution Capacities (I Can-Positive Thinking and Self-Control)

Ana was involved giving ideas and proving herself as fun and committed to the objectives of the group, although she found it difficult to express herself verbally when asked for a final reflection.

The last activity of the workshop involved writing a wish on a colored paper, putting it in a balloon and playing with it as a metaphor of what we do in life with our wishes. Ana's phrase was: "tell my parents everything that happens in my life and what I want". Ana wants understanding in her support networks, but she still has a hard time expressing what she feels to those closest to her.

\section{Summary for Ana}

In regards to resilient abilities, those referring to intrapsychic strengths (I am) can be said that Ana shows potential to transform the environment and personalize it, but she has not yet found the means to crystallize it. Furthermore, she shows the capacity to reflect on who she is, on her feelings. She recognizes the possibility of facing difficult circumstances and asking for help, in particular, she feels necessity need to express herself and to be listened, mainly by her parents. 
It is important to point out that the stress and difficulties that adolescents go through can affect their creativity and resilience [95-97]; this may be the case with Ana, because of the difficulty of unfolding her divergent potential.

On the other hand, in the skills related to I have, Ana shows expectations of becoming someone, although she is not very clear about what she wants, or she is not willing to strive to achieve her goals. Some of her goals are related to traditional roles such as "having a long life with the partner she loves". She does not feel supported by her parents, so she looks for other easy ways out. In spite of this, she knows and values her friendships, likes to collaborate, and knows how to listen to the advice given by her peers.

Finally, among the skills of "I can", it is observed that Ana does not like to study, and she still cannot identify what she is good at.

\subsubsection{Productions from Alberto}

Results from the Program on Inner Strength (I am-Active Coping and Spirituality)

In this section, we seek to analyze aspects related to autonomy, satisfaction, self-valuation of feelings of achievements and coping. One of the first activities was to draw a symbol that represented creativity. Figure 6 shows his product.

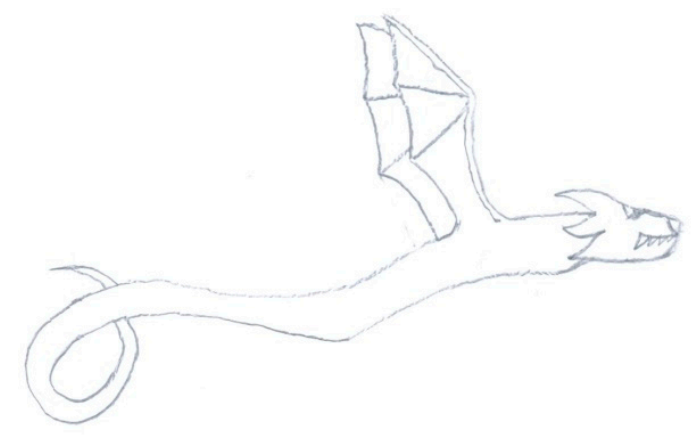

Figure 6. Symbol of Alberto's creativity.

The symbol that Alberto drew represents a dragon with its wings open, flying in one direction. It could indicate fantasy and the desire to fly or free oneself. Regarding the meaning he gives to creativity, he mentions: "For me creativity is the abstract with meaning".

Another activity that involved using imagination, making thinking more flexible, the possibility of projecting his feelings and conception of himself, was achieved with the proposal of creatively writing a story based on some images of the works of the Belgian surrealist painter René Magritte. Alberto was given the Painting of "The Lovers II" (1928) by René Magritte, and this is what he wrote:

\section{"Cloths"}

The other day I was driving and saw a beautiful woman walking by the street. I came over to talk to her and I asked her for a date, she agreed. During the date, she told me that she had to go to her house (nervous) I followed her to know what was happening and I saw her with a piece of cloth on her face. On the 3rd date I asked her about that and she said that it helped her to calm down and she felt a tingling in his face. I tried putting a cloth in my face but felt nothing until she said that only the cloth that she has is the one that creates that feeling. He saw the cloth and took it home because he liked its smell and sensation in his hands until we became greedy.

Alberto shows sensitivity and romanticism, but also his decision and persistence to achieve his goals. Thinking about it brought him joy and his face reflected happiness (because he did not express it in words). It was a task that let him recognize his values, which contributes as a protective factor. 
Regarding the work on his identity, where they had to elaborate a self-portrait from the exhibition of the contemporary art painting (see explanation of the activity in Ana's case), Alberto made the following drawing (Figure 7).

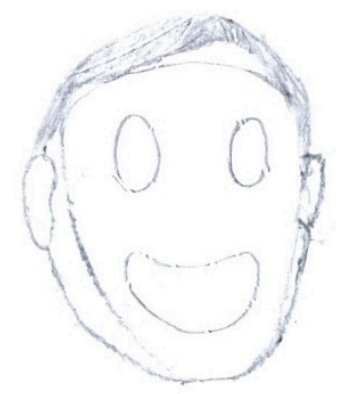

Figure 7. Alberto's Self-portrait.

Alberto's self-portrait shows a smiling face but it is covered by some kind of mask, as if he wanted to hide his true self. As seen in the story, Alberto probably hides behind a mask that prevents him from being as he would like to be, or from showing his most real feelings.

Results from the Program on External Support (I Have-Family and Social Support)

In this section we are interested in analyzing the goals, sense of action, interpersonal, family and social ties and networks, and affective judgments.

After some sessions about identity, self-knowledge, recognition of emotions, and after having presented them with the biography of some famous people who had to face great adversities like Victor Frankl, they were asked to write their own autobiography.

Alberto wrote that when he entered kindergarten, he was three years old, and that he had three friends. When he went to elementary school, he also noted that he had four friends and learned to play the piano. He says that when he was seven years old, he went to "Sixflags" (an amusement park) and was stung by a bee on his tongue. He entered high school when he was 12 years old and has three friends. It is striking that in the chronology of his life, Alberto mentions the number of friends he has had in each stage of his life, which is certainly a protective factor. However it is interesting and encouraging that he has an inspiring adult who represents his role model: "My role model is my uncle because he studied and went to New York."

On the other hand, during the cooperative play sessions, Alberto was involved in doing his job, trying to do his best even though his partner Tomás made jokes and even boycotted the work, which frustrated him a little; he showed himself to be fun and committed to the objectives of the group.

Results from the Program on Interpersonal and Conflict Resolution Capacities (I Can-Positive Thinking and Self-Control)

In this section, it is important to analyze the sense of self-efficacy, self-ability perception, learning and asking for help.

An interesting activity to get to know Alberto which allowed him to reflect on himself, was the session on "Our feelings have a color", based on the workshops proposed by Moreno [105]. In a slide show, the distinction between cold and warm colors was presented. An explanation of color theory was given and then the students had to mention what feeling the images with those colors produced in them. At the end, they were asked about the color they liked best and their feelings at the end of the activity. Alberto commented that the color he liked most was green, because he likes plants and has many of them. The color he likes least is brown, because it is dull or does not match some colors. When asked how he feels after the activity he said, "happy and anxious". Three words to describe yourself: "interesting, happy and anxious". Three words to describe how they see you: "happy, hurried and closed off". 


\section{Summary Alberto}

Regarding the resilient abilities, the ones about intra-psychic strengths (I am), Alberto shows potential to transform his environment, shows self-control, wants to be free, and happy, but he still feels locked up inside himself, hiding himself by wearing a mask. He shows himself as sensitive, romantic and persistent, and gets frustrated when others don't help in reaching common goals.

On the other hand, regarding the abilities linked to "I have", Alberto acknowledges the importance of his family as a support. He has role models which enables him to set his goals. Friendship has been a value during his school years, and he nurtures it with his personal qualities "I am kind". He cherishes teamwork and shows abilities for collaboration.

Finally, within the "I can" abilities, Alberto shows positive thoughts.

\subsubsection{Productions from Tomás}

\section{Results from the Program on Inner Strength (I Am. Active Coping and Spirituality)}

In this section we are interested in analyzing aspects related to autonomy, satisfaction, self-evaluation of feelings of achievement and coping. One of the first activities was drawing a symbol that represented creativity for them. In Figure 8 you can see their product.

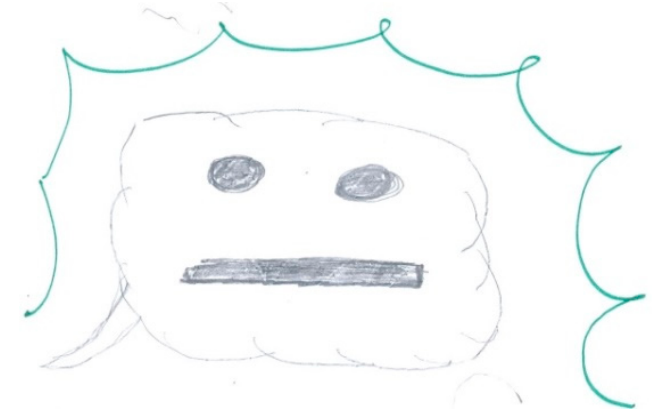

Figure 8. Symbol of Tomás' creativity.

Tomás makes a speech bubble where he adds a dialogue that in this case looks like an emoticon with a serious face. Regarding the meaning he gives to creativity he mentions: "For me creativity is a meaningless creation"

Another activity that involved using his imagination, making his thinking more flexible, the possibility of projecting his feelings and the conception of himself, was achieved with the proposal of creatively writing a story based on some images of the works of the Belgian surrealist painter René Magritte. Tomás was also given the painting of "The Lovers II" (1928) by René Magritte. He wrote a poem (Untitled):

You have much free time perhaps

Lately you have been so burdened...

In art there is the cure to your phobia;

Grazing your senses will be found.

The art is finding a sun for you.

Sun in solitude to feel happy

Believe in yourself, face consequences

Challenge your creative qualities.

Surrounded in darkness, (it) looked at me.

Holding my cheeks for pleasure...

I had to succumb to art at last.

It might be even in a blink 
Dressed in an abstract and diffuse way.

Or maybe showing seduction, pleasure.

(I only had 30 min, don't judge me)—Tomás Dixit.

Tomás shows sensitivity, optimism, self-confidence, but also some solitude and search; it seems that, in art, he can find something to lighten his burdens. The recognition of these qualities pays off as a protective factor.

About his task on his identity where they had to elaborate a self-portrait from the exhibition of the contemporary art paintings (see explanation of the activity in Ana's case), Tomás shows a clear definition of what characterizes him; he has a need to express himself, to be heard, both orally and in writing, refusing to draw. In response to the request to make a self-portrait from the paintings of some contemporary artists, Tomás did not make a drawing or a painting, but wrote a song entitled "Basureta", by the Spanish rapper known as Kase.O. This is an extract of it:

Visceral boredom, hypochondria, cosmic distress

The farthest point from the Sun, in my orbit

The pure weariness of living is my bitter tonic

Fears that I make up for with appearances

I hate myself and the belief system

Like a masochist in the hands of a sadist

It is the relationship of my soul with my conscience...

In this case, Tomás appropriates some words that attempt to define him, in which he highlights a certain boredom, anguish, fears, appearances and questioning the establish order.. However, those feelings or emotions do not paralyze him rather; they push him to the search of his own identity. When asked about his role model, he said that he was his own role model, implying a high level of self-esteem.

Results from the Program Regarding External Support (I Have-Family and Social Support)

In this section we are interested in analyzing the goals, sense of action, interpersonal, family and social ties and networks, and affective judgments.

After some sessions about identity, self-knowledge, recognition of emotions, and after having presented them with the biography of some famous people who had to face great adversities like Victor Frankl, they were asked to write their own autobiography.

Tomás defines himself as a writer; he began writing from the sixth grade onwards to confess to a girl he liked. He sent her poems by Neruda until one day he met the one who would be his idol forever: Brock Asiol (Spanish hip hop artist), who encouraged him to write to the girl, stealing the artist's poems and dedicating them to the girl. When he was in the first year of high school, he made songs taking some of Brock's phrases and a year later, he started writing his own songs. He also says that he has tried to give philosophical answers to friends' problems. He assures that what fills him the most is writing, and he would like to become a recognized singer-songwriter. He says that he has never had a girlfriend, but that the rejections he has received from the girls have inspired him to write his poems. He says he is currently indifferent and doesn't write anything he likes. Problems, as you can see, generate creativity.

During the activities, Tomás always tried to stand out or be funny, even at the expense of everyone's work. However, he showed himself to be a good counselor, with common sense to deal with the problems that usually afflict his peers in a direct way. 
Results from the Program on Interpersonal and Conflict Resolution Capacities (I Can-Positive Thinking and Self-Control)

In this section, it is important to analyze the sense of self-efficacy, self-ability perception, learning and asking for help.

Again, humor was present in his writing, and was evident in a group activity called "Exquisite Corpse" which was about collective writing. Extracting his participation from products, Tomás wrote:

How I feel

Sometimes I feel bad, but I fix the chair and I feel better" (word-play in Spanish)

Because sometimes things do not have a "how?"

Maybe it is not good to be happy ... if that bird gets praise.

Maybe what I said sounded stupid/ but all is confusing when young

It is like that by law ... because the target brings back memories

Also laying down / listening to your sweet voice

If my feelings are on diet, death, only to try to seduce you.

Feeling different condemns me: If I'm not a girl, what do I have between my legs?

He is self-judgmental, perceives his feelings as in pause; however, he mocks himself and plays with words to defy and not take himself seriously, but then he arises philosophical questions on a quest-like spirit, in the quest for love or love feelings. This is also noted in his autobiography.

Summary: Tomás

As for the resilient abilities, in the ones referring to intra-psychic (I am), Tomás deals with risks with a good attitude, shows a need to expand his feelings and communications, sometimes defying and disruptive. Despite this, he has a clear goal. He shows self-confidence and great sensibility; at the same time he shows a need of seduction and for being loved but also some boredom, angst and challenge of the status quo.

It seems like stress and his current difficulties (situational threat) can have positive components and even enable his creative process [101-103]. An example is how Tomás mentioned rejection as the trigger to write poetry.

On the other hand, regarding abilities of "I have", Tomás defines himself as a writer and has a clear goal to pursue. It is difficult to work collaboratively due to the need of being recognized in his individuality, but he learned that he can give good advice and feel appreciated by that. He uses humor as a tool to unwind the hostile environment.

Finally, within the "I can" abilities, Tomás has a high self-capacity perception, but avoids circumstances that he does not like.

\subsubsection{Program's Satisfaction Evaluation}

In order to check the effectiveness of the actions carried out during the workshop, a satisfaction questionnaire was applied. It had eleven closed questions, with five response options, where 1 means very little satisfaction and 5 the highest degree of satisfaction.

It also contained six open questions about what they liked most and least, what they had learned, and suggestions for improving the workshop.

For the three students, the most satisfactory thing was interacting with peers from other groups, in addition to considering as very positive being able to hear other opinions and different points of view. They believed that the teacher explained the concepts and activities of the workshop very well and the support material provided was enough. 
Moreover, with a high average of satisfaction (4.67), they mention have found it very rewarding to attend the course and carry out activities that are different from the ones that they usually do; the schedule seemed appropriate and the sessions were useful to get to know each other better and increase their creativity. They think that the contents can be applied in their personal development (4.33) and in their studies and daily life (4.00). What they liked the least was the place where it was taught, as they did not find it very comfortable (1.67).

In Ana's evaluation of each session, she highlights that the most significant thing for her personal learning was the opportunity to express herself: "because I express myself", the possibility to play and change her mood: "Anything as long as it changes my mood". She also says that she has learned "not to judge people" and "that I have to give my opinion about my life". When asked how she could apply this to her life she replied, "I can't explain". She would have liked the workshop to last longer.

Alberto highlights in his evaluations the interactivity and the variety of activities carried out. Among the things he learned was that "family supports you when you are in trouble", the idea of "democracy, vote"; that colors cause emotions, and he recognizes that he learned "my different moods". Among the most important ideas he learned was "teamwork", and goal setting. Alberto points out that this knowledge can be applied in life: "in personal problems; life goes on". In particular, he mentions that after one of the activities called "The Urn" that he learned: "life can't be renewed"; "people give good advice to stop suffering, let it all out". The least significant: The Tower (cooperative game), "because they threw it down many times". He liked answering the psychological tests, and wished the workshop lasted longer.

What Tomás liked the most was missing classes. He would have liked it to last longer (sometimes he felt like talking more) and felt that the teacher was very patient with him. One of the things he learned from himself is that he realized that "I am good at advising" (in the ballot box activity) and "that I can help solve other people's problems and that they like me for that." As to how he will apply what he learned to his life, he mentions "reflecting on phrases that the teacher said". The most significant thing is that "the goal is the future, it is everything."

Regarding "What was the least significant of what we did", most of the participants mentioned that everything was significant (they found no less significant things); maybe the game of the cubes, "because the classmates $t$ threw them down many times".

Regarding "What they would have omitted from the sessions", most of the participants mentioned that "everything is useful for learning", that everything had been fine.

Finally, a space was left in case they wanted to leave a free comment and the students mentioned: "I really liked the experience and it was good to learn more, and hopefully, the teacher will teach us again"; "Please do not let her leave, I will miss her".

\section{Discussion and Conclusions}

Enrichment programs for students with high intellectual abilities are key, because they allow the development of several types of skills, but also because they allow focusing on the personal and social needs in an environment of collaboration, socialization, mutual help, conflict sensitivity and their solution [106]; as proposed by authors such as Neihart [12], Henderson [19], and Grotbert [33], providing support in schools to leverage the resilience capacities of students is an adequate intervention strategy to move forward toward the education and social inclusion of all students. Specifically, employing those resources through creativity [25] in adolescence [97] allows managing students' identity problem-solving capacities in contexts where it cannot be developed in a positive way, nor is it fostered by experiences that contribute to building self-confidence and trust in others.

Therefore, this research described an intervention program to promote the development of resilience factors through creative activities in high intellectual abilities teenagers with school, family and social risk factors. With an exploratory purpose, it was also examined the related effects on creativity and resilience by completing tasks and products. 
With data gathered from the sample of students, some risk and protective factors were identified in personal, family, school and social areas. Although high abilities could become a protective factor, if the environment lacks ways to recognize, value and promote talents $[57,58,60,70]$, its potential may not unfold, and generate inadequacy emotions, low motivation, low self-esteem, and low school performance, as was shown in one of the subjects of this study. Furthermore, some family and social aspects such as their economic situation, parents' school level and occupation, as well as living in a context of scarcity, could contribute to the low expectations for and in these students.

Some researchers argue that a social, economic, and culturally deprived environment can contribute negatively to the development of talent in a subject [107]. These disadvantages may have negative effects on children because it constrains social mobility and limits the opportunities to some groups such as those in the lower economic strata, ethnic minorities and indigenous communities, among others.

Freeman's longitudinal study [108] reported that household poverty of children of high abilities children affects the possibilities to succeed in adulthood. It points out that economic poverty disables, while wealth enables, referring to the case of an intellectually outstanding student (with IQ 170) that could not continue her graduate studies at a prestigious university due to her family's severe lack of economic means; after dropping out from her studies, she had to find a modest job [109]. However, other authors [110] argue that children in low income families have overcome these apparent difficulties, even showing high performance levels, hence the importance to provide opportunities for resilience development during the schooling period.

An important thing to emphasize in the intervention context which has been presented here is that, despite internal and external conditions that could become risk factors that obstruct the development of students' potential, the support from the Principal office's personnel, sensitive to family and contextual shortcomings of students is very important; in some cases, they sought resources to help the most vulnerable population in the school. For some experts on high abilities [109], adolescence period and middle school studies are crucial to stimulate such talents; in elementary school, they could show certain attributes, but afterwards these attributes might be wasted if they are not developed and these adolescents could be erroneously considered lazy, when in fact, the system fails to stimulate them.

Once the factors that interact in the construction or inhibition of the resilience of the participants have been characterized, the skills trained during the intervention program are analyzed. This program was based on the promotion of resources for resilience, following the Grotberg models [22] which are classified into three resilient expressions: "I am", which refers to the internal conditions of the person with which the person defines himself or herself; "I have", which is the external support that the person believes they can receive, such as family and social support; and "I can", referring to problem-solving and relationship skills, including positive thinking and self-control. Likewise, the sessions were structured based on environments and content that favor creativity [74], considering the suggestions of various authors to generate a creative atmosphere [95], the elimination of creativity barriers [96], games and contemporary art [97], intrinsic motivation and sense of life [99,100]. The contents on which the activities revolved were identity, emotions and feelings, self-knowledge, problem solving, and cooperative work.

Regarding the process of developing resilient skills, students were able to reflect on their identity and their own abilities, very important aspects for self-knowledge, as evidenced in different investigations $[22,23,63,64,69]$. It was found throughout the sessions that the participants were involved in the recognition of the protective factors in the construction of their identity as adolescents with high capacity, particularly important due to their interaction in a deprived socioeconomic context [16]. They had the opportunity to experiment new creative experiences presented during the program, overcoming some initial resistances (shyness, shame, apathy), and actively engaging in their personal and group processes (reflecting, producing, exchanging opinions, and giving advice). Each participant had a complex personal history, regardless of their intellectual capacity, making the sessions a continuous challenge, in which the communication channel was playing the games, and the activity aimed to provoke divergent thinking, emotional expression, and recognition of their own 
worth. In this sense, getting involved and enjoying the proposed tasks is already a first step to activate resilient factors, since when positive emotions are activated, personal skills are put into action and self-confidence increases [26,28,37,38].

Additionally, through some dynamics, expositions and games, the participants explored some difficult circumstances of their lives, which allowed them to recognize and express the emotions that arise in such situations (frustration, anger, fear) and propose alternative solutions to those problems. Some authors point out that emotional management can transform the perception of problems from a constructive approach and deal with adversities in a more optimistic and enthusiastic way [34-36]. On the other hand, the participants in the study opened up to show their sensitivity and romanticism, which are typical of the awakening of adolescence [100] and had the opportunity to recognize other personal qualities such as kindness, patience, empathy, and a sense of humor [41], which are internal resources that function as active coping strategies [83].

It could be observed that the group of three students in this study achieved a certain level of group cohesion, in which in which all of them considered themselves as part of the group and showed solidarity with the needs of the others, which are fundamental aspects in the construction of resilience $[22,23,25]$. Interactive games, such as a rolling newsprint wheel, collective play with cubes, collective writing (exquisite corpse), group dynamics, knowing biographies of interesting characters and writing their own autobiography, allowed them to display their social and cooperation skills in different ways, and recognize the protective factors related to external support (asking for help, giving advice, having friends, the value of family, among others) [19-21]. Throughout the sessions, students recognized the value of friendship and of having role models despite their social and family circumstances, which have not allowed them to visualize their potential. Crucial to the program was the use of strategies to stimulate resilience in students with high abilities, such as role models or mentors [21] who can become significant in their lives, as well as making connections between peers with similar abilities [58]. It is therefore important to offer supportive and compensatory strategies [16] that allow both the strengthening of protective factors and the promotion of resilience factors $[10,17]$.

Activities related to positive thinking, self-control, decision making and problem solving were carried on. In this sense, the participants' perception of their abilities was somewhat irregular; while one of them was more resolute, confident in his abilities and displaying a good sense of humor, the other two were more reserved, but willing to deal with the challenges posed during the intervention, in a positive way. The activities of the program revealed some shortcomings in terms of motivation for studying and future goals, but there were also dreams and personal projections such as embarking on a journey or becoming a musician.

Thirdly, we observe how creativity was a facilitating component for the development of resilience, examined from the analysis of the students' tasks and products [30,40,92]. At the beginning of the intervention, some creativity barriers were found amongst the teenagers $[95,96]$, related to cognitive factors (low openness, learning problems, difficulties in establishing new relationships with existing ideas), affective factors (insecurity, impatience, fears, stress), or environmental factors (rigid education, lack of opportunities, criticism). As Robinson affirms, in many cases, school kills creativity [111]. This was evidenced by the results obtained by students in the test to evaluate creativity, where they showed very low percentiles in most factors. It has been documented that adverse circumstances can inhibit creativity [46,52], such as the stress and difficulties that teenagers experience. Stress decreases divergent thinking because it induces confidence in established responses and routines, giving little room for the flexibility or fluidity of ideas [44-47].

However, conflict or a situational threat has also been documented to enhance creativity in issues that are relevant to such conflict $[50,51]$. This has been evidenced during the program when one of the participants commented that he started writing poems and songs to the girl he liked, but that she did not reciprocate his feelings. Thus, from the drawings, stories, participation in collective games and other group dynamics, the participants became aware of their evolution, unblocking some of their 
inhibitors of creativity and becoming increasingly open to experimenting and creating, which have been documented by researchers as resilient factors [25,42,43].

One of the limitations of the present study was that it had few participants, which does not allow the generalization of the findings and it also limits the quantitative evaluation of the effects of the intervention. Furthermore, one of the limitations was using instruments that showed little sensitivity when measuring changes after an intervention.

It is important to note that adolescents with high abilities in Mexico receive little educational attention, since most interventions are focused particularly on elementary school children [112,113], which is why this study contributes to the visibility of both teenagers and the educational opportunities that can be offered in school contexts, especially in those with a high level of vulnerability. This research also takes into account the main aspects of developing resilience with low socioeconomic urban students [56,57], such as: (a) early identification of high skills; (b) specific interventions to reduce risk factors through creative activities; (c) counseling for both the student and the school; (d) extracurricular activities that stimulate creativity with peers with similar characteristics and significant mentors. In this sense, the recognition of their needs, strengths, and areas of opportunity, as well as working on the expression of their own identity, their emotions, and their personal and social skills, have served as ways to enhance their coping resources which prepare them to deal with adversity.

Author Contributions: Conceptualization, S.R.A. and G.L.-A.; methodology, G.L.-A., G.O.V., formal analysis, G.L.-A.; investigation, G.L.-A., S.R.A., and G.O.V., data curation, G.L.-A.; writing-original draft preparation, G.L.-A., S.R.A., writing-review and editing, G.L.-A., S.R.A., G.O.V. visualization G.L.-A., S.R.A., and G.O.V.; project administration, G.L.-A. and G.O.V. All authors have read and agreed to the published version of the manuscript.

Funding: This research received no external funding.

Conflicts of Interest: The authors declare no conflict of interest.

\section{References}

1. Luthar, S.S. Resilience in development: A synthesis of research across five decades. Dev. Psychol. 2015, 3, 739-795. [CrossRef]

2. Waller, M.A. Resilience in ecosystemic context: Evolution of the concept. Am. J. Orthopsychiat. 2001, 71, 290-297. [CrossRef] [PubMed]

3. Hartling, L.M. Fostering resilience throughout our lives: New relational possibilities. In Diversity and Development: Critical Contexts That Shape Our Lives and Relationships; Comstock, D., Ed.; Thompson Brooks/Cole: Belmont, CA, USA, 2005; pp. 337-354.

4. Luthar, S.S. Resilience and Vulnerability: Adaptation in the Context of Childhood Adversities; Cambridge University Press: Cambridge, UK, 2003.

5. Grotberg, E. The international resilience research project. In Psychologists Facing the Challenge of a Global Culture with Human Rights and Mental Health; Rosswith, R., Ed.; Pasbst Science Publishers: Graz, Austria, 1995; pp. 237-256.

6. Infante, F. La Resiliencia como proceso: Una revisión de la literatura reciente. In Resiliencia Descubriendo las Propias Fortalezas; Melillo, A., Suárez, E., Eds.; Paidós: Buenos Aires, Argentina, 2005; pp. 31-53.

7. Luthar, S.S.; Zigler, E. Vulnerability and competence: A review of research on resilience in childhood. Am. J. Orthopsychiat. 1991, 61, 6-22. [CrossRef] [PubMed]

8. Bronfenbrenner, U. Environments in developmental perspective: Theoretical and operational models. In Measuring Environment across the Lifespan: Emerging Methods and Concepts; Friedman, S.L., Wachs, T.D., Eds.; American Psychological Association: Washington, DC, USA, 1999; pp. 3-28.

9. Rutter, M. Implications of resilience concepts for scientific understanding. Ann. N. Y. Acad. Sci. 2006, 1094, 1-12. [CrossRef] [PubMed]

10. Hartling, L.M. Strengthening resilience in a risky world: It's all about relationships. Women Ther. 2008, 31, 51-70. [CrossRef]

11. Rutter, M. Resilience as a dynamic concept. Dev. Psychopathol. 2012, 24, 335-344. [CrossRef] 
12. Neihart, M. Building resilience in gifted children: Can resiliency be taught or is it innate? Underst. Our Gifted 2006, 18, 3-6.

13. Henderson, N.; Milstein, M.M. Resiliency in Schools: Making it Happen for Students and Educators; Corwin Press: Thousand Oaks, CA, USA, 2003.

14. Gómez, E.; Kotliarenco, M.A. Resiliencia Familiar: Un enfoque de investigación e intervención con familias multiproblemáticas. Rev. Latinoam. Psicol. 2011, 19, 103-132. [CrossRef]

15. Manciaux, M. La Resiliencia: Resistir y Rehacerse; Gedisa: Barcelona, Spain, 2010.

16. Kitano, M.K.; Lewis, R.B. Resilience and coping: Implications for gifted children and youth at risk. Roeper Rev. 2005, 27, 200-205. [CrossRef]

17. García-Vesga, M.C.; Domínguez-de la Ossa, E. Desarrollo teórico de la Resiliencia y su aplicación en situaciones adversas: Una revisión analítica. Rev. Latinoam. Cienc. Soc. Niñez Juv. 2013, 11, 63-77.

18. Grotberg, E. Countering depression with the five building blocks of resilience. Reaching Today's Youth. Commun. Circ. Caring J. 1999, 4, 66-72.

19. Henderson, N. Resilience in Schools and Curriculum Design. In The Social Ecology of Resilience; Springer: New York, NY, USA, 2012; pp. 297-306.

20. Villalta, M.A.; Saavedra, E. Cultura escolar, prácticas de enseñanza y resiliencia en alumnos y profesores de contextos sociales vulnerables. Univ. Psychol. 2012, 11, 67-78. [CrossRef]

21. Cyrulnik, B. ¿Por qué la resiliencia? In ¿Por qué la Resiliencia? Lo que nos Permite Reanudar la Vida; Cyrulnik, B., Anaut, M., Eds.; Gedisa: Barcelona, Spain, 2016; pp. 12-21.

22. Grotberg, E. A Guide to Promoting Resilience in Children: Strengthening the Human Spirit; Bernard Van Leer Foundation: La Haya, Holand, 1995.

23. Saavedra, E.; Villalta, M.A. Medición de las características resilientes, un estudio comparativo en personas entre 15 y 65 años. Liberabit 2008, 4, 31-40.

24. Saavedra, E.; Villalta, M. Escala de Resiliencia SV-RES, Para Jóvenes y Adultos; CEANIM: Santiago de Chile, Chile, 2008.

25. Metzl, E.; Morrell, M.A. The role of creativity in models of resilience: Theoretical exploration and practical applications. J. Creativity Ment. Health 2008, 3, 303-318. [CrossRef]

26. Metzl, E.S. Exploration of Resiliency and Creativity in Survivors of Hurricane Katrina. Ph.D. Thesis, The Florida State University, Tallahasse, FL, USA, December 2007.

27. Kim, H. Community and art: Creative education fostering resilience through art. Asia Pac. Educ. Rev. 2015, 16, 193-201. [CrossRef]

28. Thomson, E. Resilisence and adaptation. In Encyclopedia of Creativity; Runco, M.A., Pritzker, S.R., Eds.; Elsevier: Cambridge, MA, USA, 2020; Volume 2, pp. 442-447.

29. McFadden, S.H.; Basting, A.D. Healthy aging persons and their brains: Promoting resilience through creative engagement. Clin. Geriatr. Med. 2010, 26, 149-161. [CrossRef]

30. Sternberg, R.J.; Lubart, T.I. The concept of creativity: Prospects and paradigms. In Handbook of Creativity; Cambridge University Press: Cambridge, UK, 1998; pp. 3-15.

31. López Martínez, O.; Navarro, J. Rasgos de personalidad y desarrollo de la creatividad. An. Psicol. 2010, $26,151-158$.

32. Cranney, J.; Morris, S. Adaptive cognition and psychological literacy. In The Psychologically Literate Citizen: Foundations and Global Perspectives; Cranney, J., Dunn, D.S., Eds.; Oxford University Press: New York, NY, USA, 2011; pp. 251-268.

33. Grotberg, E.H. (Ed.) Resilience for Today: Gaining Strength from Adversity; Praeger: Westport, CT, USA, 2003.

34. Fredrickson, L.B.; Tugade, N.M. GAT good are positive emotions in crises? A prospective study of resilience and emotions following the terrorist attacks on the USA on September 11th 2001. J. Personal. Soc. Psychol. 2003, 84, 365-376. [CrossRef]

35. Sánchez, O.; Méndez, F.X.; Garber, J. Explanatory divergent production (EDP): The relationship between resilience and creativity. Electron. J. Res. Educ. Psychol. 2015, 13, 551-568.

36. Kashdan, T.B.; Rottenberg, J. Psychological flexibility as a fundamental aspect of health. Clin. Psychol. Rev. 2010, 30, 865-878. [CrossRef]

37. Torrance, E.P. Insights about creativity: Questioned, rejected, ridiculed, ignored. Educ. Psychol. Rev. 1995, 7, 313-322. [CrossRef] 
38. Csikszentmihalyi, M. Creativity: Flow and the Psychology of Discovery and Invention; Harper Collins Publishers: New York, NY, USA, 1996.

39. Baer, J.; Kaufman, J.C. The amusement park theoretical model of creativity. In The Cambridge Handbook of Creativity across Domains; Kaufman, J.C., Glăveanu, G.P., Baer, J., Eds.; Cambridge University Press: Cambridge, UK, 2017; pp. 8-17.

40. Plucker, J.A.; Beghetto, R.A.; Dow, G.T. Why isn't creativity more important to educational psychologists? Potentials, pitfalls, and future directions in creativity research. Educ. Psychol. 2004, 39, 83-96. [CrossRef]

41. Wolin, S.J.; Wolin, S. The Resilient Self. How Survivors of Troubled Families Rise above Adversity; Villard Books: New York, NY, USA, 1993.

42. de Caroli, M.E.; Sagone, E. Resilient profile and creative personality in middle and late adolescents: A validation study of the Italian-RASP. Am. J. Appl. Psychol. 2014, 2, 53-58.

43. Chen, X.; Padilla, A.M. Emotions and creativity as predictors of resilience among L3 learners in the Chinese educational context. Curr. Psychol. 2019, 1-11. [CrossRef]

44. Kemmelmeier, M. Cultural differences in survey responding: Issues and insights in the study of response biases. Int. J. Psychol. 2016, 51, 439-444. [CrossRef] [PubMed]

45. Amabile, T.M.; Conti, R. Changes in the work environment for creativity during downsizing. Acad. Manag. J. 1999, 42, 630-640. [CrossRef]

46. Staw, B.M.; Sandelands, L.E.; Dutton, J.E. Threat rigidity effects in organizational behavior: A multilevel analysis. Adm. Sci. Q. 1981, 26, 501-524. [CrossRef]

47. Kruglanski, A.W.; Webster, D.M. Motivated closing of the mind: "Seizing" and "freezing". Psychol. Rev. 1996, 103, 263-283. [CrossRef]

48. Goldberg, J. James Lovell: The Rescue of Apollo 13 (Library of Astronaut Biographies); Rosen: New York, NY, USA, 2004.

49. Warsitz, L. The First Test Pilot: The Story of German Test Pilot Erich Warsitz; Pen and Sword Books: Barnsley, UK, 2009.

50. De Dreu, C.K.; Nijstad, B.A. Mental set and creative thought in social conflict: Threat rigidity versus motivated focus. J. Pers. Soc. Psychol. 2008, 95, 648-661. [CrossRef]

51. Smith, G.J.W.; Van Der Meer, G. Creativity through psychosomatics. Creativity Res. J. 1994, 7, $159-170$. [CrossRef]

52. Byron, K.; Khazanchi, S.; Nazarian, D. The relationship between stressors and creativity: A meta-analysis examining competing theoretical models. J. Appl. Psychol. 2010, 95, 201-212. [CrossRef] [PubMed]

53. Runco, M.A. Creativity and its discontents. In Creativity and Affect; Shaw, M.P., Runco, M.A., Eds.; Ablex: Norwood, NJ, USA, 1994; pp. 102-123.

54. Walton, A.P.; Kemmelmeier, M. Creativity in its social context: The interplay of organizational norms, situational threat, and gender. Creativity Res. J. 2012, 24, 208-219. [CrossRef]

55. Luthar, S.S.; Cicchetti, D.; Becker, B. The construct of resilience: A critical evaluation and guidelines for future work. Child. Dev. 2000, 71, 543-562. [CrossRef] [PubMed]

56. Morales, E.E. Linking strengths: Identifying and exploring protective factor clusters in academically resilient low-socioeconomic urban students of color. Roeper Rev. 2010, 32, 164-175. [CrossRef]

57. Dole, $\mathrm{S}$. The implications of the risk and resilience literature for gifted students with learning disabilities. Roeper Rev. 2000, 23, 91-96. [CrossRef]

58. Neihart, M. Risk and resilience in gifted children: A conceptual framework. In Social and Emotional Development of Gifted Children; Neihart, M., Reis, S.M., Robinson, N.M., Moon, S.M., Eds.; Prufrock Press: Waco, TX, USA, 2002; pp. 113-124.

59. López, V.; Sotillo, M. Giftedness and social adjustment: Evidence supporting the resilience approach in Spanish-speaking children and adolescents. High Abil. Stud. 2009, 20, 39-53. [CrossRef]

60. Worrell, F.C. Talented students and resilient at-risk students: Similarities and differences. Gifted Child. 2007, $1,2-5$.

61. Neihart, M. Dimensions of underachievement, difficult contexts, and perceptions of self: Achievement/ affiliation conflicts in gifted adolescents. Roeper Rev. 2006, 28, 197-204. [CrossRef]

62. Reis, S.M.; Colbert, R.D.; Hébert, T.P. Understanding resilience in diverse, talented students in an urban high school. Roeper Rev. 2004, 27, 110-120. [CrossRef]

63. Fredrickson, B.L.; Branigan, C. Positive emotions broaden the scope of attention and thought-action repertoires. Cogn. Emot. 2005, 19, 313-332. [CrossRef] 
64. Gardynik, U.M.; McDonald, L. Implications of risk and resilience in the life of the individual who is gifted/learning disabled. Roeper Rev. 2005, 27, 206-214. [CrossRef]

65. Paludo, K.I.; Loos-Sant'ana, H.; Sant'ana-Loos, R.S. A identidade da pessoa com altas habilidades/superdotação sob a ótica do sistema teórico da afetividade ampliada. PsicoDom 2013, 12, 79-95.

66. Chen, X.; Cheung, H.Y.; Fan, X.; Wu, J. Factors related to resilience of academically gifted students in the chinese cultural and educational environment. Psychol. Sch. 2017, 55, 107-119. [CrossRef]

67. Friborg, O.; Barlaug, D.; Martinussen, M.; Rosenvinge, J.H.; Hjemdal, O. Resilience in relation to personality and intelligence. Int. J. Methods Psychiatr. Res. 2005, 14, 29-42. [CrossRef]

68. Neihart, M.; Yeo, L.S.; Pfeiffer, S.I.; Shaunessy-Dedrick, E.; Foley-Nicpon, M. Psychological issues unique to the gifted student. In APA Handbook of Giftedness and Talent; American Psychological Association (APA): Washington, DC, USA, 2018; pp. 497-510.

69. Ballam, N. Fostering resilience in 'at-risk' gifted and talented young people. In Handbook of Giftedness and Talent Development in the Asia-Pacific; Smith, S., Ed.; Springer: Singapore, 2020; pp. 1-18.

70. Acle Tomasini, G.; Ordaz Villegas, G. Resiliencia y aptitudes sobresalientes en niños de zonas urbano-marginadas. Ideacción 2010, 31, 288-299.

71. Rosenstock, L.; Riordan, R.; Mendelssohn, J.; Audet, L.; Patston, T.; Renzulli, J.; Baer, J.; Garrett, T.; Niu, W.; Zhou, Z.; et al. Nurturing Creativity in the Classroom; Cambridge University Press: New York, NY, USA, 2010.

72. Neihart, M.; Pfeiffer, S.I.; Cross, T.L. The Social and Emotional Development of Gifted Children: What Do We Know? 2nd ed.; Prufrock Pres: Waco, TX, USA, 2015.

73. Beghetto, R.A.; Kaufman, J.C. Classroom contexts for creativity. High Abil. Stud. 2014, 25, 53-69. [CrossRef]

74. Beghetto, R. Creativity in teaching. In The Cambridge Handbook of Creativity across Domains; Kaufman, J.C., Glăveanu, G.P., Baer, J., Eds.; Cambridge University Press: Cambridge, UK, 2017; pp. 549-564.

75. INEGI. Censo Nacional de Gobierno Federal. Mexico, 2017. Available online: https://www.inegi.org.mx/ programas/cngf/2017/ (accessed on 15 May 2020).

76. Yin, R.K. Case Study Research: Disign and Methods, 5th ed.; Sage: Thousand Oaks, CA, USA, 2014.

77. Creswell, J.W. Research Design: Qualitative, Quantitative, and Mixed Methods Approaches, 2nd ed.; Sage: London, UK, 2003.

78. Raven, J.C.; Court, J.H.; Raven, J. Manual de Test de Matrices Progresivas. Escalas Coloreada, General y Avanzada; Paidós: Buenos Aires, Argentina, 2008.

79. Ordaz, G.; Acle, G.; Reyes, L.I. Development of an academic self-concept for adolescents (ASCA) scale. J. Behav. Health Soc. Issues 2013, 5, 117-130.

80. Torrance, E.P. Torrance Tests of Creative Thinking: Spanish Directions Manual Figural Forms A and B; Scholastic Testing Service Inc.: Bensenville, IL, USA, 2008.

81. Barcelata, B.E.; Rodríguez, R. Desarrollo y validación de la Escala de Recursos Potenciales para la Resiliencia para Adolescentes. Rev. Latinoam. Med. Conducta 2016, 6, 75-87.

82. De la Torre, S. TAEC. Test de Abreacción para Evaluar la Creatividad; Escuela Española: Madrid, Spain, 1991.

83. Barcelata, B.E. Adaptación y Resiliencia Adolescente en Contextos Múltiples; Manual Moderno: Mexico City, Mexico, 2018.

84. Corona, H.F.; Peralta, V.E. Prevención de conductas de riesgo. Rev. Méd. Clín. Las Condes 2011, 22, 68-75. [CrossRef]

85. Torrance, E.P. Predictive validity of the Torrance tests of creative thinking*. J. Creative Behav. 1972, 6, $236-262$. [CrossRef]

86. Guilford, J.P. Frames of reference for creative behavior in the arts. In Creativity: Its Educational Implication; Gowan, J.C., Khatena, J., Torrance, E.P., Eds.; Kendall/Hunt: Dubuque, IA, USA, 1981; pp. 152-155.

87. Helfand, M.; Kaufman, J.C.; Beghetto, R.A. The four-c model of creativity: Culture and context. In The Palgrave Handbook of Creativity and Culture Research; Glaveanu, V.P., Ed.; Palgrave Macmillan: London, UK, 2016; pp. 15-36.

88. Maker, C.J. Creativity, intelligence, and problem solving: A definition and design for cross-cultural research and measurement related to giftedness. Gift. Educ. Int. 1993, 9, 68-77. [CrossRef]

89. Csikszentmihalyi, M. Implications of a systems perspective for the study of creativity. In Handbook of Creativity; Sternberg, R.J., Ed.; Cambridge University Press: New York, NY, USA, 1999; pp. 313-335.

90. Renzulli, J.S. What makes giftedness? Reexamining a definition. Phi Delta Kappan 2011, 92, 81-88. [CrossRef] 
91. Collins, M.A.; Amabile, T.M. Motivation and creativity. In Handbook of Creativity; Sternberg, R.J., Ed.; Cambridge University Press: New York, NY, USA, 1999; pp. 297-312.

92. Renzulli, J.S. The three-ring conception of giftedness: A developmental model for promoting creative productivity. In Reflections on Gifted Education: Critical Works by Joseph S. Renzulli and Colleagues; Reis, S.M., Ed.; Prufrock Press: Waco, TX, USA, 2016; pp. 55-90.

93. Coppari, N.; Barcelata, B.E.; Bagnoli, L.; Codas, G. Efectos de la edad, el sexo y el contexto cultural en la disposición resiliente de los adolescentes de Paraguay y Mexico. Rev. Psicol. Clíni. Niños Adolesc. 2018, 5, 16-22.

94. Grotberg, E.H. Nuevas tendencias en resiliencia [introducción]. In Resiliencia: Descubriendo las Propias Fortalezas; Melillo, A., Suárez, N., Eds.; Paidós: Buenos Aires, Argentina, 2004; pp. 19-30.

95. Betancourt, J. Atmósferas Creativas 2: Rompiendo Candados Mentales; Manual Moderno: Mexico City, Mexico, 2008.

96. Waisburd, G. Creatividad y Transformación. Teoría y Técnicas; Trillas: Mexico City, Mexico, 2012.

97. Belver, M.H.; Ullán, A.M. La Creatividad a Través del Juego; Amarú: Salamanca, Spain, 2007.

98. Betancourt, J.; Valadez, D. Atmósferas Creativas. Juega, Piensa y Crea; Manual Moderno: Mexico City, Mexico, 2000.

99. Sedas, S.W.; Molina, A.P.; Ocón, M.M.; Islas, J.M. Un programa para despertar resiliencia, motivación intrínseca y un sentido de propósito en jóvenes. In Proceedings of the Actas del 1er Congreso Internacional de Innovación Educativa, Ciudad de Mexico, Mexico, 15-17 December 2014; Tecnológico de Monterrey: Monterrey, Nuevo León, 2014; pp. 11-120.

100. SSP. Taller de Resiliencia Para Adolescentes; Subsecretaría de Prevención y Participación Ciudadana: Mexico City, Mexico, 2010.

101. Garaigordobil, M.T.; Fafoaga, J.M. Diseño y Evaluación de un Programa de Intervención Socioemocional para Promover la Conducta Prosocial y Prevenir la Violencia; MEC: Madrid, Spain, 2005.

102. Martínez, M.; Castelló, A. Los perfiles de la excepcionalidad intelectual. In Educación, aprendizaje y Cognición. Teoría en la Práctica; Castañeda, S., Ed.; Manual Moderno: Mexico City, Mexico, 2004.

103. Zacatelco, R.F.; Acle, T.G. Modelo de identificación de la capacidad sobresaliente. Rev. Mex. Investig. Psicol. 2009, 1, 41-43.

104. Alexopoulou, A.; Batsou, A.; Drigas, A. Resilience and academic underachievement in gifted Students: Causes, consequences and strategic methods of prevention and intervention. Int. J. Online Biomed. Eng. 2019, 15, 78-86. [CrossRef]

105. Moreno, C. Nuestros sentimientos tienen color. Talleres de arte en la educación infantil y primaria: Influencia emocional del color visto desde el arte contemporáneo. In Proceedings of the Aprendemos la teoría del color, experimentando. Memorias del II Congreso internacional de Psicología y Educación, Ciudad de Panama, Panamá, 13-17 August 2012; Psychology Investigation Corp: Ciudad de Panamá, Panama, 2012.

106. Acereda, E.A. Niños Superdotados; Pirámide: Madrid, Spain, 2010.

107. Olszewski-Kubilius, P. The role of the family in talent development. In Handbook of Giftedness in Children; Springer: Boston, MA, USA, 2008; pp. 53-70.

108. Freeman, J. The emotional development of gifted and talented children. Gift Talent Int. 2006, 21, 20-28. [CrossRef]

109. Sekowski, A.; Siekańska, M. National academic award winners over time: Their family situation, education and interpersonal relations. High Abil. Stud. 2008, 19, 155-171. [CrossRef]

110. Tomlinson, C.A.; Ford, D.Y.; Reis, S.M.; Briggs, C.; Strickland, C.A. In Search of the Dream: Designing Schools and Classrooms that Work for High Potential Students from Diverse Cultural Backgrounds; National Association for Gifted Children and National Research Center on the Gifted and Talented: Washington, DC, USA, 2004.

111. Robinson, K.; Aronica, L. Creative Schools: The Grassroots Revolution That's Transforming Education; Viking: New York, NY, USA, 2015.

112. Ordaz, G.; Acle, G.; Armenta, M.C.I. Crear con Ciencia: Programa de enriquecimiento para el desarrollo de la creatividad mediante experimentos científicos. In Programas de Intervención para Niños con Altas Capacidades y su Evaluación; Valadez, M.D., López-Aymes, G., Borges, M.A., Betancourt, J., Zambrano, R., Eds.; Manual Moderno: Mexico City, Mexico, 2016; pp. 93-118.

113. Secretaría de Educación Pública. Propuesta de Intervención: Atención Educativa a Alumnos y Alumnas con Aptitudes Sobresalientes; SEP: Mexico City, Mexico, 2016.

(C) 2020 by the authors. Licensee MDPI, Basel, Switzerland. This article is an open access article distributed under the terms and conditions of the Creative Commons Attribution (CC BY) license (http://creativecommons.org/licenses/by/4.0/). 